\title{
Informe Nacional: evolución de la infección por VIH/SIDA Chile 1984-2012
}

\author{
Departamento de Epidemiología. División de Planificación Sanitaria \\ Ministerio de Salud de Chile \\ Diciembre, 2013
}

National Report: evolution of HIV/AIDS infection in Chile, 1984-2012

\section{Contenidos}

Resumen ejecutivo

Antecedentes.

Metodología.

Limitaciones

Resultados

I. Notificaciones de infecciones por VIH y SIDA

1984-2012.

1. Tendencia 1984-2012.

2. Distribución por sexo.

3. Casos confirmados por el Instituto de Salud

Pública entre los años 2004 y 2012.

4. Casos notificados respecto a las muestras positivas procesadas en el Instituto de Salud Pública años 2004 al 2012.

II. Análisis de la incidencia de la notificación por quinquenios 1988 a 2012.

1. Distribución por edad.

2. Distribución geográfica.

3. Distribución por nivel de escolaridad.

4. Distribución según vía de transmisión

5. Distribución por etapa diagnóstica en la primera notificación.

6. Casos notificados que han cambiado a etapa SIDA

III. Otras variables de caracterización.

1. Nacionalidad de las personas notificadas.

2. Conductas sexuales declaradas.

IV. Mortalidad por SIDA Chile 1990-2011

V. Análisis de los determinantes sociales de la salud 1. Educación sexual y medios de comunicación..

2. Inmigración y pueblos originarios.

3. Género

Conclusiones

Comentarios

Agradecimientos

Referencias

Anexos

\section{Resumen ejecutivo}

Desde el año 1984 hasta el 2012, tanto la tasa de casos notificados en etapa SIDA como de infección por VIH (de aquí en adelante denominada solamente: etapa VIH), han ido en aumento, descendiendo en el 2006, para luego mostrar un aumento sostenido hasta el 2009 y luego volver a descender en el año 2010. Sin embargo, en el año 2011 se presenta la mayor tasa de notificación del período, que para SIDA es de 6,0 por cien mil habitantes (habs.) y para etapa VIH de 9,6 por cien mil habs. En el 2012, la tasa se mantuvo relativamente estable. El principal grupo poblacional afectado es el de adultos entre 20 y 39 años.

En la etapa SIDA, el número de casos en hombres supera ampliamente al de mujeres. La razón hombre: mujer ha descendido en el tiempo, llegando en el 2012 a 5,8 en etapa SIDA mientras que en etapa VIH se observa una estabilización llegando a 4,7 hombres por cada mujer.

En los tres últimos quinquenios, las regiones que concentraron las mayores tasas de infección por VIH/ SIDA, fueron: Arica y Parinacota, Tarapacá, Antofagasta, Valparaíso y la Región Metropolitana (RM). La principal vía de transmisión fue la vía sexual, representando $99 \%$ en el quinquenio 2008-2012. La vía más declarada es la práctica de homo/bisexualidad concentrando el $61 \%$ de los casos en este mismo quinquenio. Del total de casos de infección por VIH/SIDA notificados en Chile entre 1988 y $2012,56 \%$ se notificó en etapa VIH mientras que $44 \%$ fue notificado tardíamente.

A partir del año 1990, se comenzaron a registrar las primeras defunciones a causa del SIDA, siendo, hasta el año 2011, 87\% de ellas en hombres. La tasa de mortalidad por SIDA experimentó un aumento progresivo hasta el 2001, año en que se observó la tasa más alta del período (3,5 por cien mil habs.). No obstante, en los últimos once años (2002-2012) la mortalidad por SIDA ha mostrado una relativa estabilización llegando el 2011 a 2,7 por cien mil habs. 


\section{Antecedentes}

Desde 2001, año en el que se cree que la epidemia alcanzó su punto máximo en el mundo, el número de nuevas infecciones disminuyó en 33\% al 2012; sin embargo, el número total de personas infectadas con VIH aumentó $17,7 \%$ en relación al 2001 y representó la cifra más elevada hasta el momento (35,3 millones de personas infectadas). Esta situación se puede explicar por el continuo aumento de nuevas infecciones por el VIH sumado a una expansión significativa del acceso al tratamiento anti-retroviral, hecho que ha permitido reducir las muertes relacionadas con el SIDA y prolongar la vida ${ }^{1}$.

En el mundo, el número de nuevas infecciones para el año 2012 se estimó que fue de 2,3 millones, correspondiendo $97 \%$ de ellos a personas de países con ingresos bajos y medios. El $86 \%$ de ellas fue en adultos, de los cuales $47 \%$ fueron mujeres y $41 \%$ jóvenes entre 15 y 24 años.

El número de personas que mueren por causas relacionadas con el SIDA disminuyó a 1,6 millones en 2012, ello significó una reducción de 30\% respecto del índice máximo observado en el año 2006 (2,3 millones $)^{1}$.

Está descrito que la vulnerabilidad al VIH es a menudo profundizada por características demográficas y socioculturales como la pertenencia a grupos étnicos, raza y discapacidad, prosperando en contextos de pobreza, desigualdad social, violencia e inestabilidad política ${ }^{2}$. África subsahariana sigue siendo la región más afectada por el VIH. En 2012, alrededor de 70\% de todas las personas con infección por VIH residían en esta región, que representa sólo el $12 \%$ de la población mundial ${ }^{1}$.

En los últimos 25 años, los factores sociales, individuales y colectivos han moldeado la epidemia de la infección por VIH en América Latina. En general, la epidemia en esta región se mantiene estable, permaneciendo en los últimos años cifras entre 85.000 y 100.000 nuevas infecciones por año. Sin embargo, el número total de personas infectadas por VIH ha seguido aumentando desde 1,1 millones en 2001, hasta un estimado de 1,5 millones en el 2012, debido mayormente a la disponibilidad del tratamiento anti-retroviral que tiene una cobertura aproximada de $70 \%$ en las Américas. La mayor parte de la epidemia de infección por VIH en esta región se concentró en población de hombres que tienen sexo con hombres (HSH) $)^{3}$.

Los aspectos sociales y culturales forman parte de los determinantes sociales de la salud (DSS), que ofrecen una orientación de la interpretación de la conducta de los individuos, de sus estilos de vida y relaciones sociales. La Organización Mundial de la Salud (OMS) y la Organización Panamericana de la Salud (OPS) recomiendan que éstos sean considerados dentro de los estudios de los sistemas de salud ${ }^{4}$.
En Chile, la epidemia de infección por VIH/SIDA se inició en 1984 con la detección de 6 casos, provenientes de las regiones de Valparaíso, Bío-Bío y Metropolitana. En el año 1985, la RM notificó la primera mujer en el país. Según datos de Spectrum se estimó que el año 2012 existían 39.000 personas infectadas por el VIH en el país ${ }^{5}$.

La planificación de la respuesta a la epidemia de infección por VIH requiere disponer de información sistemática sobre sus distintos aspectos, por lo que es preciso contar con sistemas de información epidemiológica. Es así que en Chile, la vigilancia epidemiológica de infección por $\mathrm{VIH} /$ SIDA está regulada por el Decreto Supremo N 158/04 $\mathrm{y}$ tiene como objetivo conocer la magnitud, tendencia, características y factores de vulnerabilidad y riesgo frente a la epidemia, con el fin de generar estrategias para su prevención y control atingentes a la situación nacional.

El objetivo de este informe es evaluar la tendencia y caracterizar el comportamiento socio-demográfico y de algunos elementos conductuales de la epidemia de infección por VIH/SIDA en Chile, a partir de la información que entrega el formulario de notificación de casos, además de integrar nuevas formas de análisis (interpretativos, comparativos) que den cuenta de un desarrollo más profundo del comportamiento del sistema sanitario y epidemiológico del país a través de su impacto social.

\section{Metodología}

Se realizó un estudio descriptivo de los casos de infección por VIH/SIDA. Para ello se trabajó con los datos proporcionados por el sistema de notificación de casos en línea* y con los datos provenientes de los certificados de defunción validados por el Departamento de Estadísticas e Información en Salud (DEIS) del Ministerio de Salud (MINSAL) de Chile.

Para validar la información contenida en la base de notificaciones, se realizó una búsqueda de casos repetidos por código o RUN, revisándose la coherencia entre:

- Sexo con la condición de gestación.

- Edad y fecha de nacimiento.

- Construcción del código y las fechas de nacimiento y RUN. Esta revisión se hizo a partir de 2011.

Se corrigieron los casos correspondientes y se eliminaron casos repetidos. Toda la validación se realizó previa revisión por las Secretarías Regionales MinisterialesSEREMIS notificadoras.

\footnotetext{
* Los casos son ingresados al sistema una vez que han sido etapificados o bien cuando han fallecido. Antes del año 2009 se utilizaba el "Formulario para notificación de caso" en reemplazo del boletín ENO.
} 
El análisis del presente informe se organiza en cinco ítems:

I. La tendencia e incidencia desde 1984 al 2012 considera el total de casos notificados en estos años por etapa diagnóstica, además de un análisis por sexo. El cálculo de las tasas se realizó por cien mil habs., utilizando las proyecciones de población del Instituto Nacional de Estadística (INE). De un total de 29.092 notificaciones realizadas entre los años 1984 y 2012, 129 personas no registraron información sobre la etapa diagnóstica. Por lo tanto, cuando se analizó según etapa, se trabajó sobre un total de 28.963 de personas que registraron esta variable. En este ítem, también se realizó el análisis de los casos confirmados por el Instituto de Salud Pública (ISP) y se relacionaron con el estado de notificación. Para ello se trabajó con la información disponible en los boletines del ISP y con los datos de muestras confirmadas que se envían al MINSAL. Para validar esta base de datos con el objetivo de analizar casos positivos y no muestras, se consolidó la información del ISP desde el 2004 al 2012 eliminando códigos duplicados y considerando como caso primario el que registra la fecha de primera confirmación, siendo eliminados los registros de casos con el mismo código y fechas posteriores de confirmación.

II. El análisis socio-demográfico de los últimos 25 años se presenta por quinquenios* $^{* *}$ entre los años 1988 y 2012, considerando un total de 28.844 casos que registraron etapa y 28.963 que registraron sexo. Se analizaron las variables de etapa, edad, distribución geográfica, nivel de escolaridad, vías de exposición, etapa de la primera notificación y cambio de etapa. Para el cálculo de las tasas quinquenales se utilizaron las proyecciones de población del INE del quinquenio a mitad del período ${ }^{* * *}$ y se amplificaron por cien mil habs.

III. La caracterización de "otras variables" como nacionalidad, se realizó a partir de los últimos tres quinquenios. Las variables relacionadas al comportamiento sexual, uso de preservativo y número de parejas sexuales en los últimos 12 meses, se analizaron agrupadas en el quinquenio 2008-2012. Para este análisis se utilizaron porcentajes, trabajándose sobre $100 \%$ de variables respondidas.

IV. La mortalidad por SIDA se analizó según tendencia desde 1990 a $2011^{* * * *}$, además de la caracterización de la mortalidad del quinquenio 2007-2011. El cálculo de las tasas se realizó por cien mil habs., utilizando las proyecciones anuales de población del INE.
V. Los DSS fueron orientados desde una metodología cualitativa e interpretativa que buscó recoger datos socioculturales de la población con riesgo de infección por el VIH. A partir de un estudio de casos con un alcance exploratorio se investigaron las conductas y orientaciones sexuales, los factores de riesgos y la generación de nuevos fenómenos sociales que han surgido a partir de los datos arrojados por el presente informe, tomando como referencia otras mediciones cuantitativas efectuadas en el país (encuesta Instituto Nacional de la Juventud-INJUV).

A través de un razonamiento inductivo se recolectaron datos de relevancia para generar conclusiones generales que vincularan los DSS con el comportamiento mostrado en la descripción de los casos notificados desde 1984 a 2012, abordándose las siguientes temáticas:

- Educación sexual y medios de comunicación: relaciones sociales, redes sociales, medios de información, uso de preservativos, capital social.

- Inmigración y pueblos originarios: cultura, valores, normas, sistema de salud, vulnerabilidad, discriminación, conductas sociales.

- Género: feminización, orientaciones sexuales, conductas sexuales.

En el procesamiento se utilizó el paquete estadístico SPSS versión 19.0, y Microsoft Excel versión 2010. Los mapas fueron generados utilizando el programa Arcgis 10.0 .

\section{Limitaciones}

La información utilizada es la que se recoge a partir de las notificaciones realizadas en el formulario específico de notificación, donde se requiere que la persona cuente con la etapificación de la infección, razón por la cual, es importante remarcar que el informe sólo presenta tasas de incidencia de nuevos diagnósticos notificados, por lo que a partir de esta fuente de información no es posible conocer la tasa de incidencia de infecciones por VIH.

Las notificaciones se realizan de acuerdo al año en que las personas fueron etapificadas, lo que no necesariamente es coincidente con el año que el ISP confirma los casos. Esto debido a que existe una latencia de tiempo desde que una persona es confirmada hasta que accede al control, momento en el cual es etapificado, en base a exámenes de

\footnotetext{
** Los quinquenios corresponden a los períodos 1988-1992, 1993-1997, 1998-2002, 2003-2007 y 2008-2012.

*** Quinquenio 1988-1992, población del año 1990; quinquenio 1993-1997, población del año 1995; quinquenio 1998-2002, población del año 2000; quinquenio 2003-2007, población del año 2005; quinquenio 2008-2012 población del año 2010.

**** Considerando como tales los Códigos CIE-9 (hasta 1996): 279.5, 279.6 y 279.7 y CIE-10 (desde 1997): B20-B24.
} 
laboratorio (recuento de linfocitos T CD4 y carga viral) y etapa clínica (de acuerdo a definición de caso).

Dado que se realizó una validación más acabada de la construcción de los códigos a partir del año 2011, esto podría influir en la integralidad de las comparaciones entre lo notificado y lo confirmado, porque desde el 2010 hacia atrás producto de códigos errados, podrían no existir coherencia con los confirmados por el ISP impactando en una menor proporción de casos confirmado que hayan sido notificados.

\section{Resultados}

\section{Notificaciones de infecciones por VIH y SIDA 1984-2012}

En Chile, la epidemia de infección por VIH/SIDA se inició en 1984, con la detección de 6 personas, distribuidas en las regiones de Valparaíso, Bío-Bío y Metropolitana. En 1985, la RM notificó la primera mujer en el país.

Desde sus inicios hasta el año 2012, las notificaciones de infección por VIH/SIDA alcanzan a 29.092 casos y de ellos, 28.963 registran etapa diagnóstica.

\section{Tendencia 1984-2012}

\section{Etapa SIDA}

Desde el año 1984 la tasa de notificación muestra un constante aumento; entre 0,1 y 6,0 casos por cien mil habs., presentando una disminución en el año 2006 $(2,5$ por cien mil habs.) para luego mostrar un aumento sostenido hasta el 2009 y luego volver a bajar el 2010, presentándose en el 2011 la mayor tasa de notificación por SIDA (6,0 por cien mil habs.), lo que representa un aumento porcentual de $46 \%$, con respecto al 2010 . En el 2012, la tasa se mantiene relativamente estable $(5,4$ por cien mil habs.); sin embargo, es necesario considerar que esta cifra se considera preliminar, pudiendo experimentar una variación (Figura 1).

Cabe destacar que durante el período 2007-2012 los casos notificados aumentaron en ambos sexos, debido probablemente a la implementación del sistema de noti- ficación en línea, que ha mejorado la oportunidad de la notificación, y a la ejecución de la Auditoría Ministerial sobre "Procesos involucrados desde el diagnóstico hasta la notificación para vigilancia epidemiológica del VIH" que comenzó a realizarse desde el último trimestre del año 2008 y que ha continuado como proceso permanente, incluyéndose dentro del sistema de monitoreo y evaluación que año a año desarrolla el Programa Nacional de VIH e ITS. Ello ha motivado en los equipos de atención clínica y de vigilancia epidemiológica la comunicación de resultados del examen de VIH a las personas que son positivas al test para VIH y su búsqueda activa para, una vez conocida su situación serológica, se incorporen al control de la infección por VIH/SIDA, posibilitándose su notificación. Este aumento también puede atribuirse al cambio introducido desde el 2007 en la definición de caso de SIDA, de acuerdo a recomendaciones de los organismos técnicos internacionales. En efecto, las mejoras en los métodos de diagnóstico y de etapificación posibilitan una adecuada clasificación, que establece el cruce entre el recuento de linfocitos T CD4 y la etapa clínica, de modo que personas asintomáticas pero con un recuento linfocitario bajo $\left(C D 4<200 / \mathrm{mm}^{3}\right)$ quedan clasificadas en etapa SIDA, mientras que según la definición usada anteriormente se clasificaban en etapa VIH.

El incremento de casos observado en el año 2011, podría atribuirse además, a las políticas y estrategias implementadas a partir del año 2010, enfocadas en la promoción del testeo de infección por VIH, como una forma de contribuir al diagnóstico precoz y tratamiento oportuno.

El incremento del SIDA a través de los años, reside fundamentalmente en el aumento de las tasas del sexo masculino. Las mujeres han tenido un aumento paulatino, manteniéndose relativamente estacionarias sus tasas durante los últimos cuatro años (Anexo 1).

\section{Etapa $\mathrm{VIH}$}

La tasa de notificación presenta un aumento sostenido hasta el 2003, posteriormente se inicia un leve descenso para nuevamente aumentar en el 2008, observándose un
Figura 1. Tasa de notificación de SIDA por sexo y total país. Chile 1984-2012*. Fuente: Formulario de notificación $\mathrm{VIH} / \mathrm{SIDA}$. Depto. Epidemiología, MINSAL. *Información preliminar.

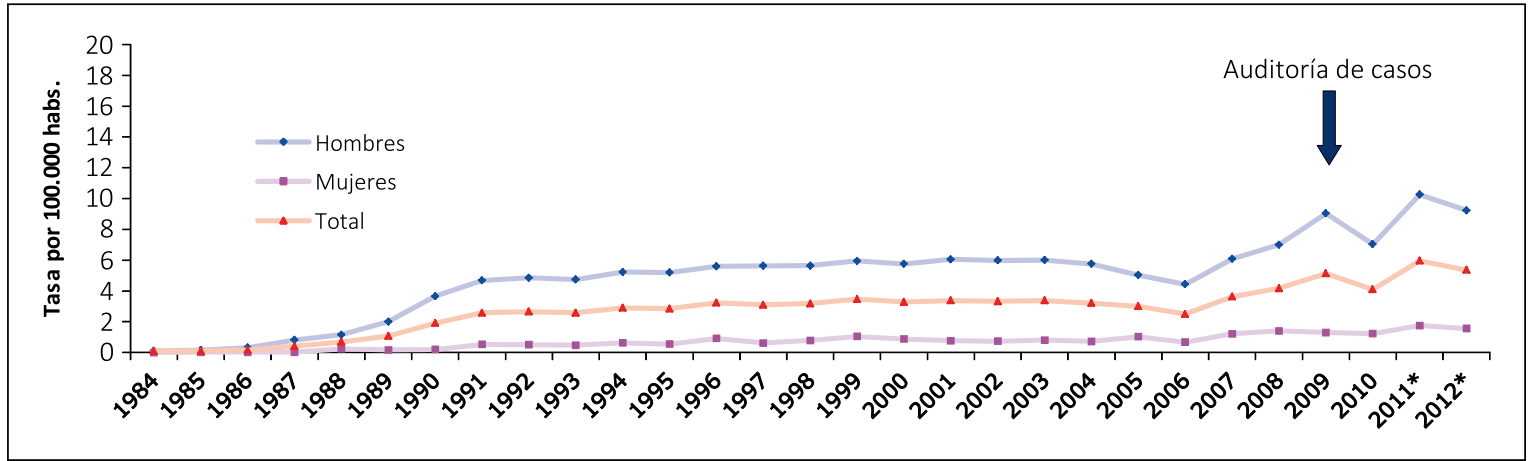




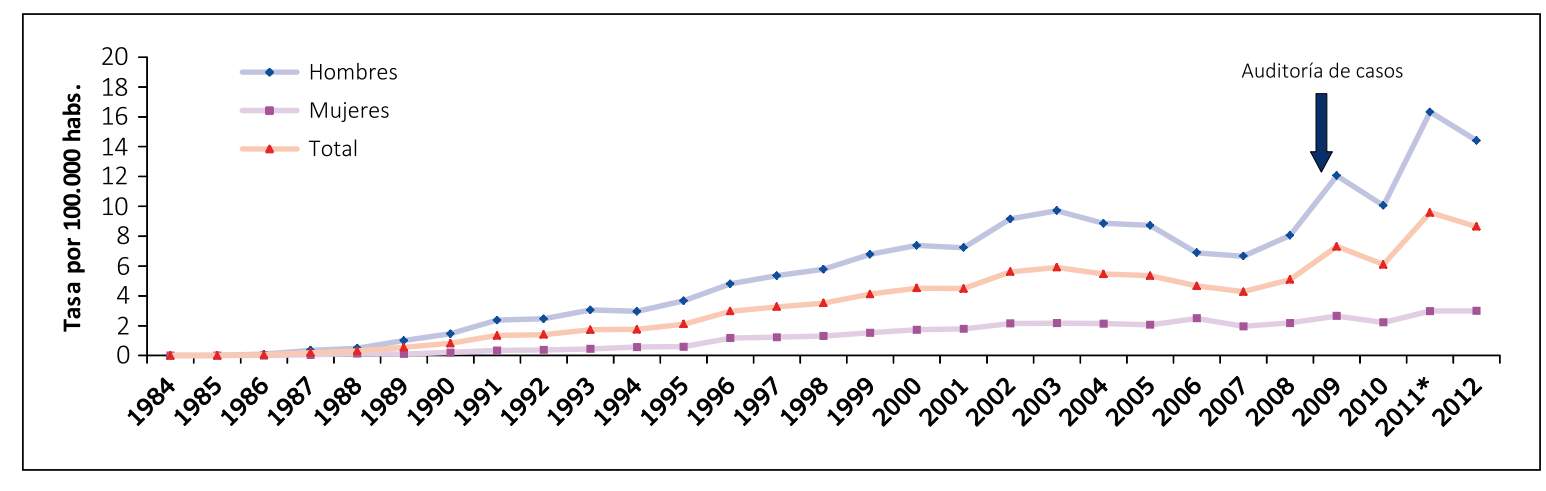

Figura 2. Tasa de notificación de etapa VIH por sexo y total país. Chile 1984-2012*. Fuente: Formulario de notificación $\mathrm{VIH} / \mathrm{SIDA}$. Depto. Epidemiología, MINSAL. *Información preliminar. pico en el año 2011 (9,6 por cien mil habs.) representando un aumento porcentual de $57 \%$ con respecto al 2010 . Durante el 2012, la tasa ha experimentado una relativa estabilización, pero es necesario considerar que esta cifra es aún preliminar (Figura 2).

Las tasas de notificación de los hombres se observan con una tendencia al aumento y tiende a la estabilidad desde el 2011. Las mujeres muestran un aumento paulatino y sostenido en el tiempo; no obstante, las tasas se mantienen igual en los últimos dos años (Anexo 1).

Probablemente, las causas del incremento entre los años 2007 y 2012 sean las mismas que las indicadas en el aumento de notificaciones de los casos de SIDA. Además, se incorpora el hecho que desde el 2011 se comenzó a desarrollar el proceso "monitoreo de la comunicación de resultados positivos" a los usuarios y su posterior derivación a control, lo que podría estar mejorando la oportunidad del ingreso a control y, como consecuencia, de la notificación.

\section{Distribución por sexo}

Desde el diagnóstico de los primeros casos de infección por VIH en Chile, el número de casos en hombres supera ampliamente al de mujeres, tanto en etapa VIH como en etapa SIDA; sin embargo, las mujeres a través de los años muestran un aumento sostenido, que en etapa SIDA es discreto, mientras que en etapa VIH el aumento es marcado. Además, se demuestra que en etapa SIDA la razón hombre: mujer, ha ido en descenso estabilizándose en los últimos tres años, llegando a 5,8 en el año 2012. En etapa VIH, se observa una relativa estabilización alrededor de 4 hombres por cada mujer desde el año 1996. Esta razón presenta una leve baja durante los años 2006 hasta el 2008, para comenzar a subir desde el 2009 en adelante hasta llegar a 5,4 en el año 2011; la cifra preliminar del año 2012 alcanzó a 4,7. Lo anterior revela un incremento en la brecha entre ambos sexos a expensas del mayor incremento en los hombres versus las mujeres (Figuras 3 a y b).

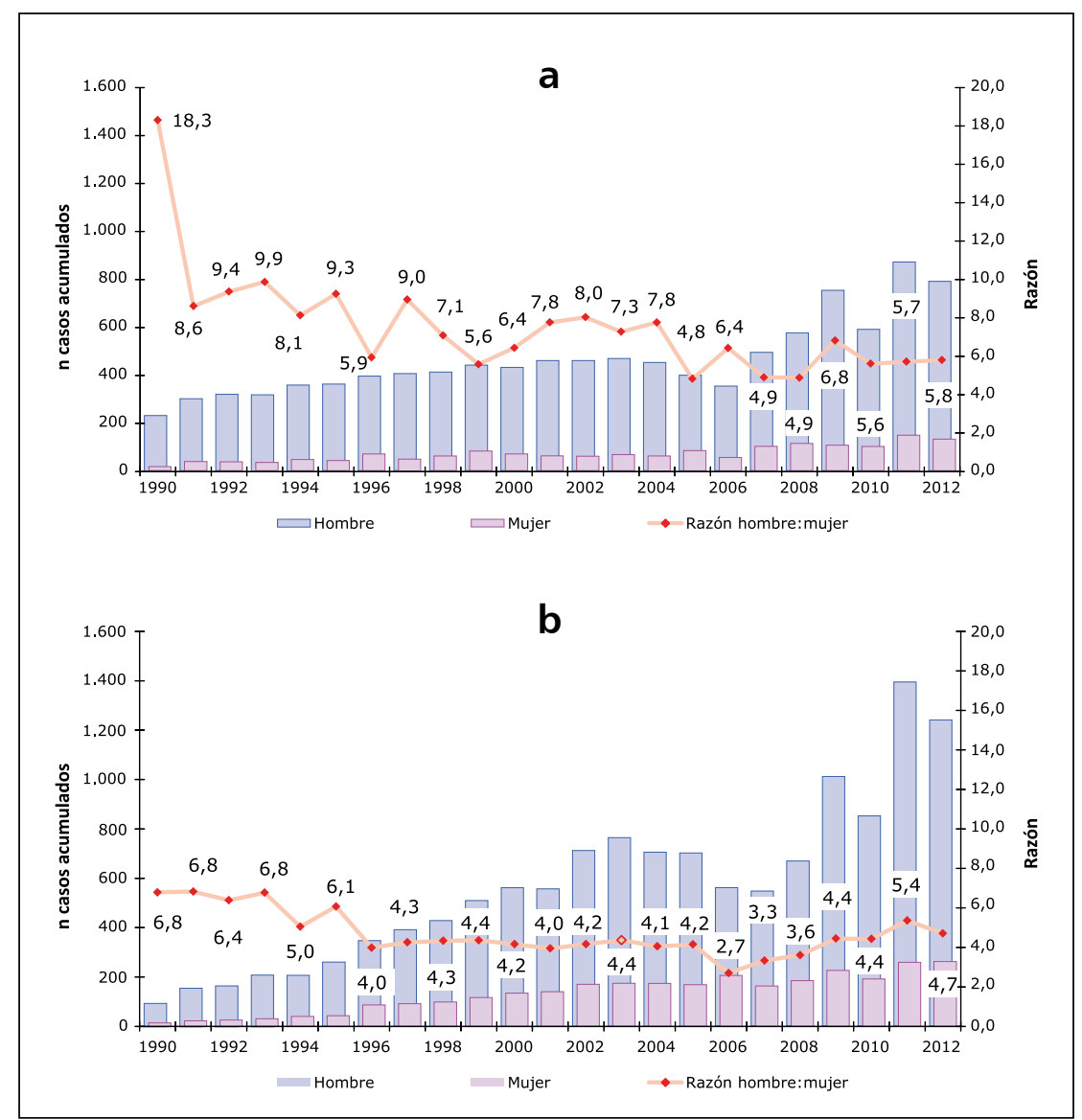

Figura 3. a: Casos de SIDA notificados según sexo y razón hombre mujer. Chile 2008-2012*. b: Casos de VIH notificados según sexo y razón hombre mujer. Chile 2008-2012*. Fuente: Formulario de notificación VIH/SIDA. Depto. Epidemiología, MINSAL. *Información preliminar.

\section{Casos confirmados por el Instituto de Salud Pública entre los años 2004 y 2012}

Según informa el ISP, al analizar sólo los casos confirmados por el ISP (independientes del número de muestras tomadas por persona), se observa que existe un aumento 
sostenido de los nuevos diagnósticos seropositivos desde el año 2004 con una tasa de 12,5 por cien mil habs., estabilizada entre el 2009-2011 hasta alcanzar el 2012 una tasa de 19,8 por cien mil habs., la mayor de todo el período.

Durante el período comprendido entre enero de 2009 y diciembre de 2012, el ISP recibió un total de 28.421 muestras para la confirmación de infección por VIH, de las cuales 13.477 fueron confirmadas $(47,4 \%)$ y aunque este porcentaje de confirmación se mantuvo sobre $40 \%$ durante todo el período, fue en el año 2012 cuando se presentó la proporción más alta llegando a $51 \%$. Coherentemente con ello, ese año fue el que mostró el mayor número de muestras recibidas (n: 7.260) y confirmadas (n: 3.673$)^{7}$.

$\mathrm{Al}$ analizar las tasas de personas confirmadas por el ISP y la de notificaciones según muestra la Figura 4, las

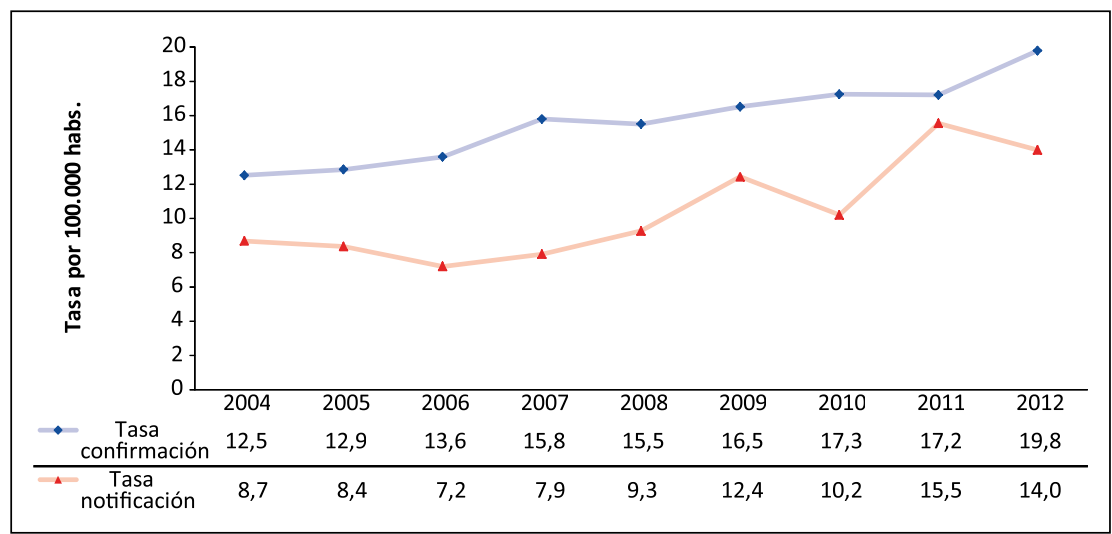

Figura 4. Tasas de confirmaciones y tasas de notificación VIH/SIDA. Chile 2004-2012*. Fuente: Confirmaciones ISP, Formulario de notificación VIH/SIDA. Depto. Epidemiología, MINSAL. *Información preliminar.

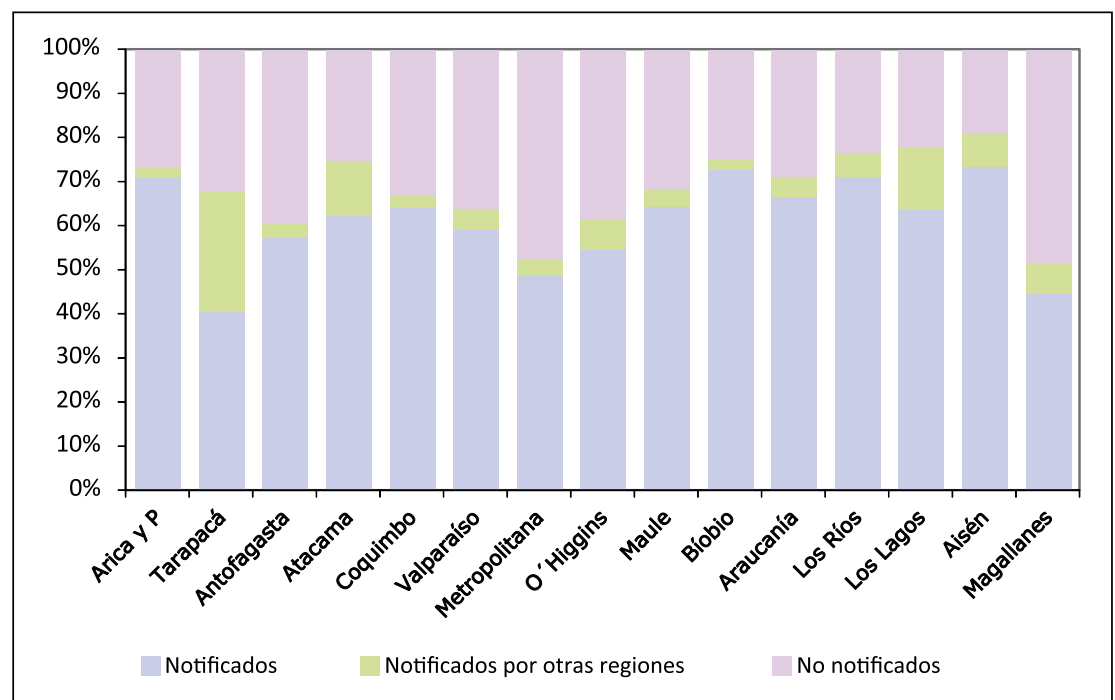

Figura 5. Distribución de casos confirmados por el ISP, según regiones y estado de notificación. Chile 2004-2012*. Fuente: Formulario de notificación VIH/SIDA. Depto. Epidemiología, MINSAL/Casos confirmados VIH. ISP. *Información preliminar. tasas de confirmación realizadas por el ISP son mayores a las tasas de los casos notificados durante todo el período en estudio, superando las confirmaciones desde 24 a 50\% a la tasas de notificaciones, destacando que las mayores diferencias porcentuales se encuentran en los años 2006 y 2007. Esta situación cambió a partir del 2011, donde la diferencia se estrechó siendo sólo de 9,1\%. En el año 2012 aumentó esta brecha hasta llegar a 29\% de diferencia porcentual; no obstante, cabe destacar que este aumento se puede atribuir, entre otros factores, al tiempo de latencia entre la confirmación y el ingreso a control. Por lo tanto, los casos confirmados en los últimos meses del año pueden haber sido notificados durante el año 2013, por lo que no son parte del presente informe.

La diferencia de tasas entre confirmación y notificación evidencia la subnotificación de los casos, la que bien puede deberse a falta de notificación de los casos en los formularios específicos desde los establecimientos o porque las personas confirmadas no han ingresado a control.

Según las cifras recogidas por el Programa Nacional de Prevención y Control del VIH e ITS, de total de casos confirmados por el ISP provenientes del sector público de salud durante el año 2012, 94,7\% de las personas conocen su condición de serología positiva al VIH.

\section{Casos notificados respecto a las muestras positivas procesadas en el Instituto de Salud Pública años 2004 al 2012}

Del total de casos confirmados por el ISP entre los años 2004 y 2012 (n: 23.720), 59\% se encontró notificado en el sistema en línea de vigilancia epidemiológica de la infección por VIH/SIDA.

La distribución porcentual de casos notificados en relación a los confirmados por el ISP, experimenta un cambio a medida que pasa el tiempo, aumentando el porcentaje de notificación en forma retrospectiva. Esto porque no necesariamente un caso confirmado en determinado año será notificado ese mismo período, lo que responde al tiempo de latencia observado entre el diagnóstico de laboratorio y el ingreso a control.

Como se observa en la Figura 5, se evidencia una movilidad geográfica de los casos debido a que la región donde las personas se realizan el examen (que corresponde a la informada por el ISP), no siempre es la misma en la que ingresan a control, lugar en que son notificadas; esta movilidad impacta en el porcentaje regional de los casos notificados. Como se muestra en la Figura 5, Tarapacá, Atacama y Los Lagos muestran los mayores porcentajes de casos notificados por otras regiones del país. Del total de personas confirmadas por el ISP, $9 \%$ es notificada en una región distinta a la que se registra la toma del examen.

En las regiones con mayor población como la RM ocurre que personas de otros lugares del país se toman el examen en la capital, para luego volver a su región de 
origen, lo que dificulta el ingreso oportuno a control y, por ende, la notificación del caso. Sin embargo, existen normativas $^{8}$ que señalan las acciones y procedimientos administrativos que tanto el sector público como privado deben realizar, para ubicar a las personas, comunicarles el resultado y derivarlos al control correspondiente.

La región con menor proporción de casos notificados en la misma región que confirmó el caso, es Tarapacá (41\%), seguida por Magallanes (45\%) y RM (49\%). El resto del país muestra valores sobre $53 \%$ de casos notificados, destacando que las regiones con el mayor porcentaje de notificaciones son Aysén, Bío-Bío, Arica y Parinacota y Los Ríos, todas ellas con porcentajes sobre $70 \%$ de casos confirmados y notificados por la misma región.

\section{Análisis de la incidencia de la notificación por quinquenios 1988 a 2012}

\section{Distribución por edad}

$\mathrm{Al}$ analizar los casos de infección por VIH/SIDA por grupos de edad se observa que en todos los quinquenios las tasas más altas se encuentran entre los 20 y 49 años, representando este grupo $84 \%$ del total de casos notificados. En todos los quinquenios analizados, las personas entre 30 a 39 años registran las tasas más elevadas, destacándose que en el último quinquenio el grupo de 20 a 29 años alcanzó tasas muy similares a las del grupo de 30 a 39 años. Los adolescentes (15-19 años) presentan uno de los mayores aumentos porcentuales a través del tiempo, incrementando en el último quinquenio $72 \%$ respecto del anterior. A partir de los 20 años hasta los 65 años, el resto de los grupos etarios aumentan entre 30 y $56 \%$ entre el segundo y último quinquenio. Se destaca que los casos de infección por VIH/SIDA en niños entre 5 y 9 años en el período 2008-2012 doblan la tasa presentada en el quinquenio anterior (Tabla 1).

En la Figura 6 se muestra la evolución del comportamiento según grupos de edad, observándose que en etapa SIDA las mayores tasas de notificación se concentran entre los 30 a 49 años, destacándose en el último período un aumento de las tasas en todos los grupos etarios. Es importante considerar que los niños entre 5 y 9 años duplican la notificación respecto al quinquenio 2003-2007. Relevante también es lo sucedido en el grupo de adolescentes quienes en el último quinquenio superan en 136\% la tasa del quinquenio anterior (Figura 6 a y Anexo 2).

En etapa VIH, las mayores tasas se concentran entre los 20 a 39 años, un decenio antes que en etapa SIDA. Durante el último quinquenio, el grupo de 20 a 29 años experimentó un brusco ascenso superando al de 30 a 39 años, diferenciándose de años anteriores en que ambos grupos decenales mostraban tasas similares. Se destaca además que las tasas sobre los 30 años presentan menores

\begin{tabular}{|c|c|c|c|c|c|c|c|c|c|c|}
\hline \multirow[t]{2}{*}{ Edad } & \multicolumn{2}{|c|}{ 1988-1992 } & \multicolumn{2}{|c|}{ 1993-1997 } & \multicolumn{2}{|c|}{$1998-2002$} & \multicolumn{2}{|c|}{ 2003-2007 } & \multicolumn{2}{|c|}{ 2008-2012 } \\
\hline & $\mathrm{n}$ & Tasa* & $\mathbf{n}$ & Tasa* & $\mathbf{n}$ & Tasa* & $\mathbf{n}$ & Tasa* & $\mathbf{n}$ & Tasa* \\
\hline $0-4$ & 19 & 1,3 & 47 & 3,2 & 65 & 4,9 & 70 & 5,7 & 45 & 3,6 \\
\hline $5-9$ & 2 & 0,2 & 5 & 0,3 & 11 & 0,7 & 13 & 1,0 & 23 & 1,9 \\
\hline $10-14$ & 3 & 0,3 & 5 & 0,4 & 8 & 0,5 & 11 & 0,7 & 17 & 1,3 \\
\hline $15-19$ & 70 & 5,7 & 81 & 6,9 & 191 & 14,4 & 227 & 15,5 & 397 & 26,7 \\
\hline $20-29$ & 703 & 28,0 & 1.404 & 56,5 & 1.851 & 76,7 & 2.085 & 83,6 & 3.635 & 130,6 \\
\hline $30-39$ & 562 & 28,2 & 1.386 & 58,2 & 2.280 & 90,7 & 2.305 & 93,0 & 3.167 & 131,6 \\
\hline $40-49$ & 274 & 19,9 & 564 & 34,9 & 1.014 & 51,4 & 1.373 & 58,4 & 2.024 & 81,6 \\
\hline $50-59$ & 95 & 10,0 & 244 & 21,9 & 436 & 32,9 & 546 & 35,0 & 873 & 45,8 \\
\hline $60-69$ & 42 & 6,3 & 73 & 9,5 & 119 & 13,9 & 169 & 16,7 & 284 & 23,5 \\
\hline 70 y más & 9 & 1,8 & 16 & 2,7 & 31 & 4,3 & 45 & 5,2 & 54 & 5,4 \\
\hline Total & 1.779 & 13,5 & 3.825 & 26,6 & 6.006 & 39,0 & 6.844 & 42,1 & 10.519 & 61,5 \\
\hline
\end{tabular}

aumentos porcentuales que los mostrados en etapa SIDA. El grupo de 15 a 19 años experimentó una de las mayores alzas porcentuales entre el tercer y último quinquenio (67\%), seguido por el grupo entre 20 y 29 años (59\%). Ocurrió además un importante aumento porcentual de los niños entre los 5 y 14 años entre el tercer y cuarto quinquenio (Figura 6 b y Anexo 2).

En ambas etapas la infección por VIH muestra un disminución alrededor de $39 \%$ en los niños bajo 5 años de edad.

En ambos sexos las mayores tasas se concentran en el grupo de 20 a 49 años. Por su parte, las mujeres muestran mayores tasas en el grupo de 20 a 29 años exceptuando el último quinquenio en que las tasas de este grupo tienden a estabilizarse siendo superadas por el grupo de 30 a 39 años. Los hombres presentan tasas elevadas entre los 30 a 39 años, destacándose el último quinquenio en que el grupo de hombres de 20 a 29 años alcanza valores similares a la de hombres de 30 a 39 años (Figuras 7 a y b).

Si bien en ambos sexos todos los grupos etarios aumentaron sus tasas, exceptuando el de niños bajo 5 años, uno de los mayores incrementos porcentuales entre el cuarto y último quinquenio se presentó en el grupo de 15 a 19 años en hombres, aumentando 94\% (Anexo 3).

\section{Distribución geográfica}

Según distribución territorial, las regiones que concentran las mayores tasas de infección por VIH/SIDA en los tres últimos quinquenios son las del extremo norte y centro del país, siendo éstas: Arica y Parinacota, Tarapacá, Antofagasta, Valparaíso y la RM. Las regiones del extremo sur presentan las menores tasas a nivel nacional (Anexo 4). 


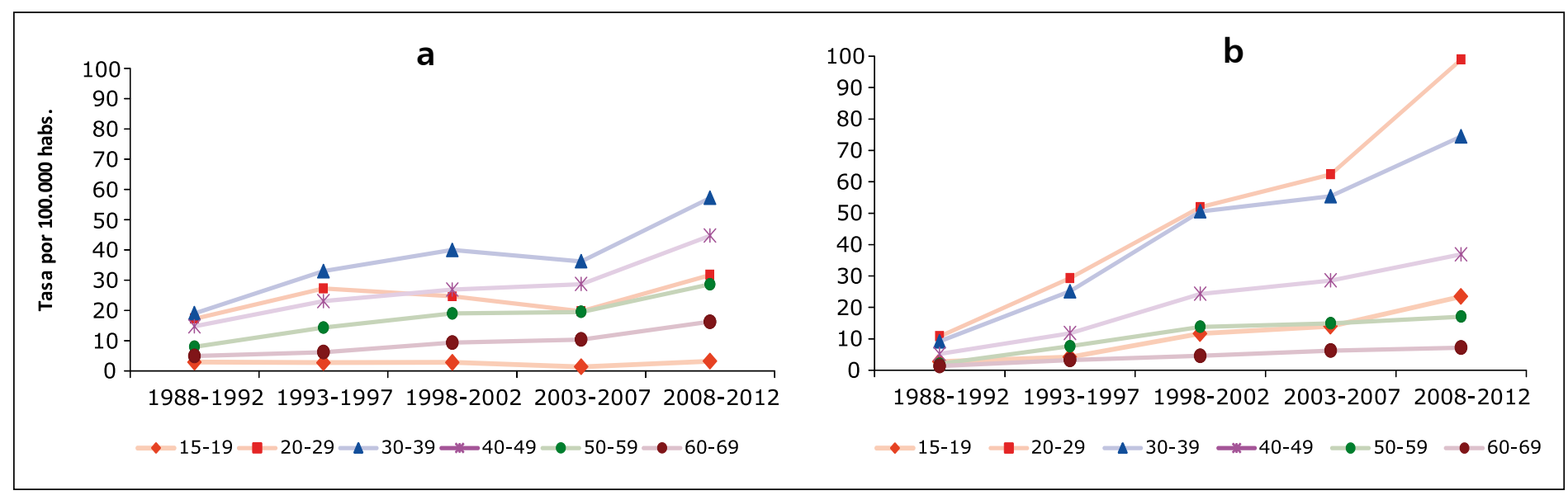

Figura 6. a: Tasa de notificación por SIDA según grupos de edad y quinquenio, Chile 1987-2012*. b: Tasa de notificación por VIH según grupos de edad y quinquenio, Chile 1987-2012*. Fuente: Formulario de notificación VIH/SIDA. Depto. Epidemiología, MINSAL. *Información preliminar.

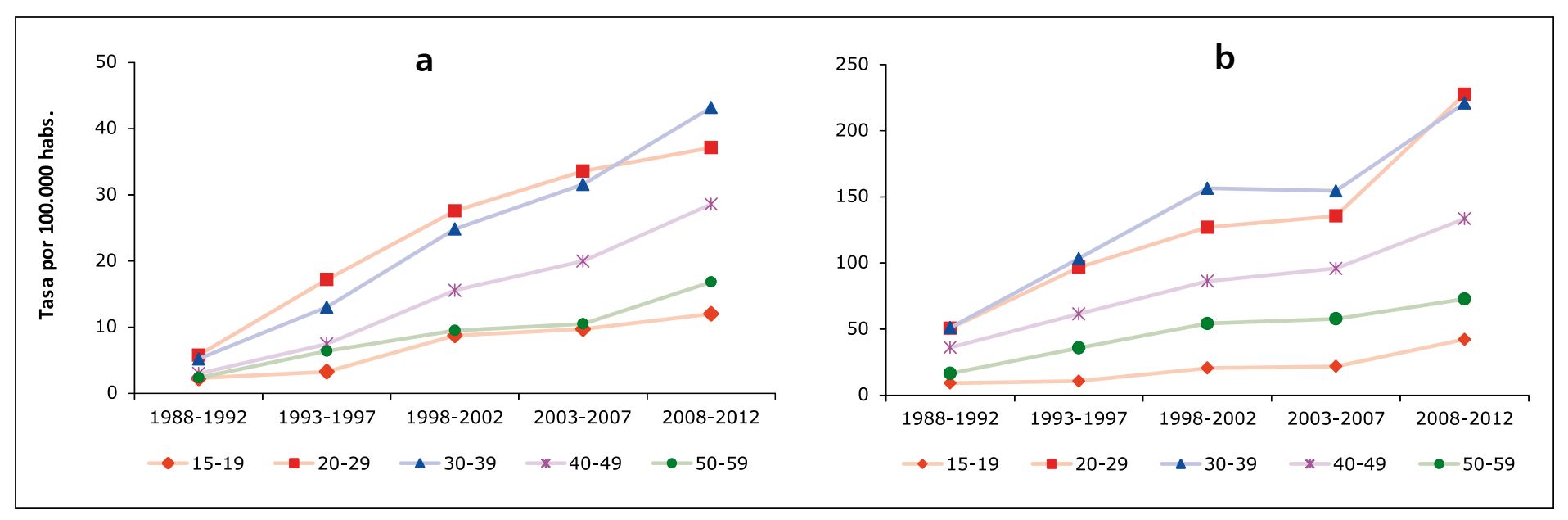

Figura 7. a: Tasa de notificación por VIH/SIDA en mujeres, según grupos de edad y quinquenio, Chile 1988-2012*. b: Tasa de notificación por VIH/SIDA en hombres, según grupos de edad y quinquenio, Chile 1988-2012*. Fuente: Formulario de notificación VIH/SIDA. Depto. Epidemiología, MINSAL. *Información preliminar.

Según se puede comparar en los mapas 1 y 2 , en la mayoría de las regiones durante los dos últimos quinquenios las tasas de infección por VIH son mayores que las mostradas en etapa SIDA. La Región de Arica y Parinacota presenta las tasas más elevadas, tanto de VIH como de SIDA en este período y triplicando la tasa nacional en los años 2008-2012. En los tres últimos quinquenios la Región de Tarapacá ocupó el segundo lugar del país, desplazando a la RM (Anexo 4).

A nivel nacional, $60 \%$ de las personas son notificadas en etapa de VIH. Por su parte, las regiones del extremo sur presentan los mayores porcentajes de notificación en etapas tempranas de la infección, siendo Aysén y Magallanes quienes notifican en 90 y $76 \%$ de los casos, respectivamente, en etapa VIH, seguida de Antofagasta (67\%) y la RM (64\%). Las regiones del Libertador B.
O’Higgins y Valparaíso son quienes presentan mayores porcentajes de notificación en etapa tardía (SIDA).

En el mapa 1, se observa cómo a través del tiempo la tasa de SIDA ha ido en aumento en todo el territorio nacional. En los dos primeros quinquenios las tasas más elevadas se presentaban en la RM y Valparaíso, con valores que se encontraban muy por sobre el resto de país. Posteriormente, se sitúan dentro de las regiones con las mayores tasas de SIDA.

Desde el tercer quinquenio se observa cómo en la zona norte del país aumentan las tasas de notificación por SIDA, siendo a partir de este período que las regiones de Arica y Parinacota y Tarapacá presentan las tasas más elevadas de SIDA, llegando a 70,3 y 38,5 casos por cien mil habs., respectivamente, en el quinquenio 2008-2012. 


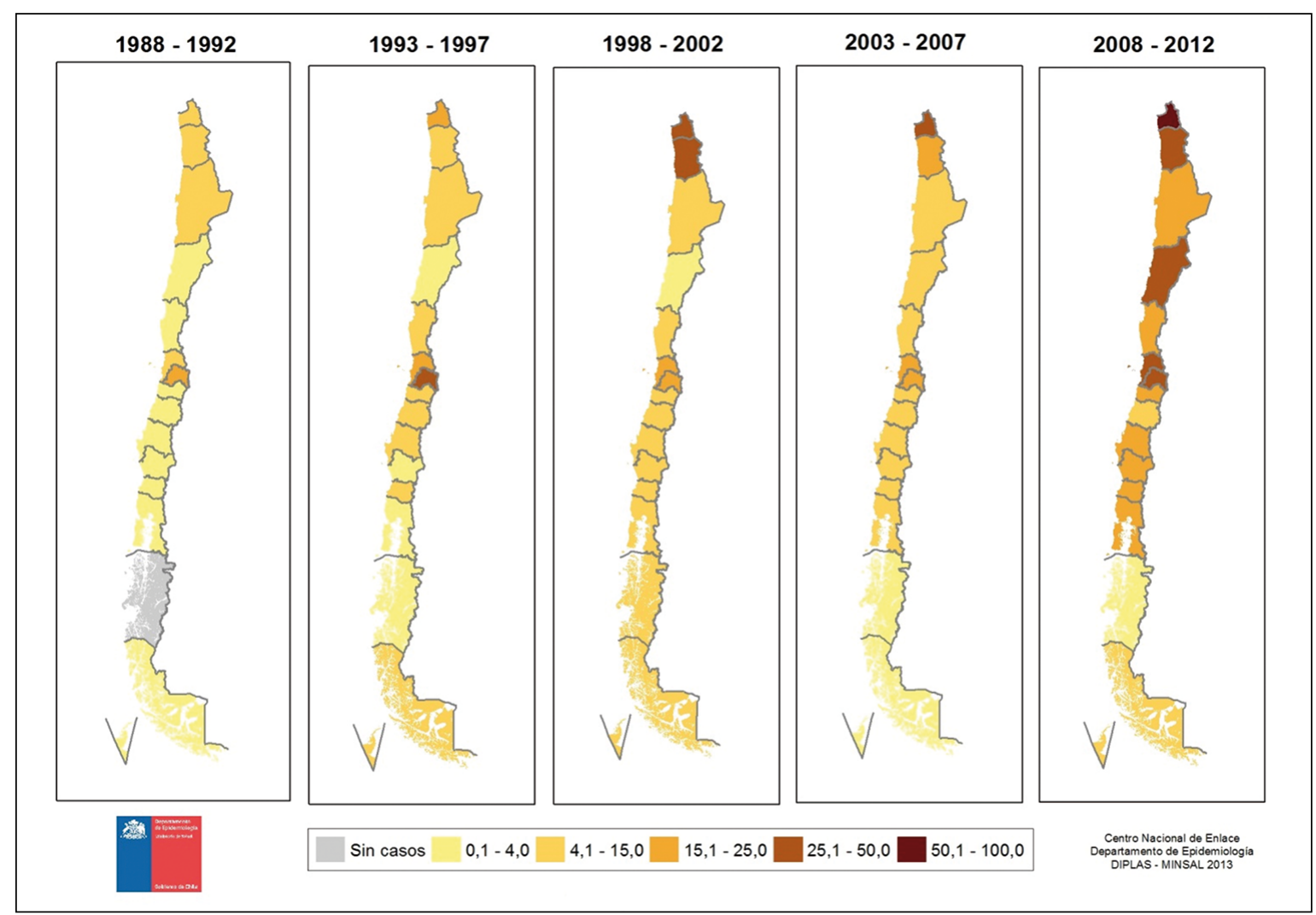

Mapa 1. Tasa* de notificación de SIDA según región y quinquenios, 1988-2012. *Tasas por 100.000 habitantes.

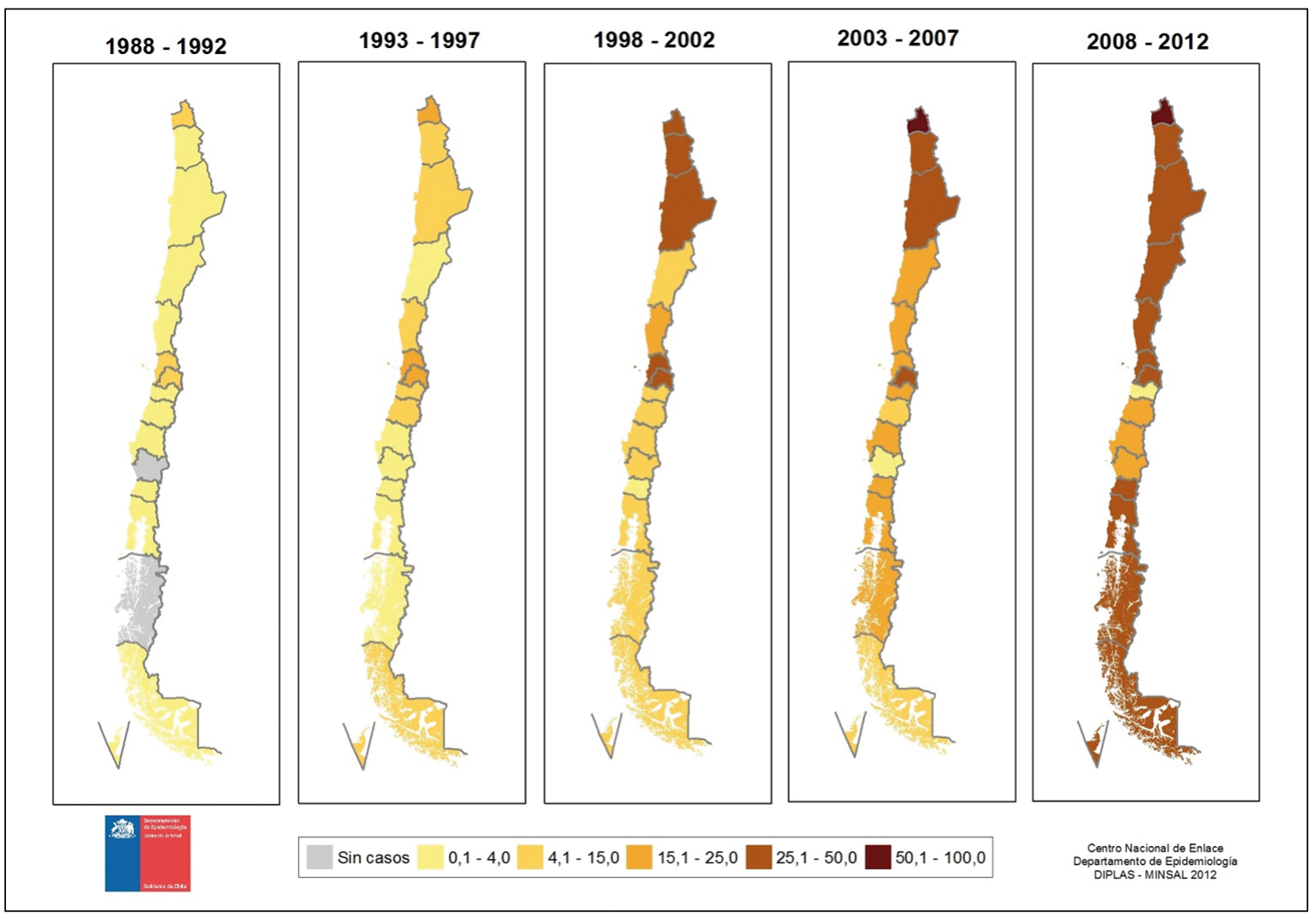

Mapa 2. Tasa* de notificación de VIH según región y quinquenios, 1988-2012. *Tasas por 100.000 habitantes. 
Se destaca que en el último quinquenio, las regiones de Atacama, Coquimbo, La Araucanía, Los Ríos y Los Lagos muestran los mayores aumentos porcentuales, siendo todos ellos sobre $100 \%$. Es relevante considerar que en el último quinquenio, Atacama igualó la tasa de la RM. Las menores tasas se encuentran el extremo sur con valores muy por debajo de las cifras nacionales (Anexo 4).

En etapa VIH, desde el segundo quinquenio se observa cómo en la zona norte del país aumentan las tasas de notificación, destacando que desde el tercer quinquenio la Región de Arica y Parinacota (96,8 por cien mil habs.) ha presentado la tasa más alta del país, superando en 2,6 veces la tasa del país en el período 2008-2012. Lo mismo sucede con las regiones de Tarapacá, Antofagasta y Metropolitana, las que a través de los años mantienen las tasas más elevadas (Mapa 2 y Anexo 4).

A partir del tercer quinquenio las tasas de notificación en etapa VIH son superiores a las de SIDA.

$\mathrm{Si}$ bien las menores tasas de infección por VIH se concentran en el extremo sur del país, las regiones de Magallanes (51\%) y Aysén (47\%) son las que presentan uno de los mayores aumentos porcentuales entre el cuarto y último quinquenio al igual que La Araucanía (48\%) y Los Lagos (47\%) (Anexo 4).

\section{Distribución por nivel de escolaridad}

Los casos notificados de etapa VIH y SIDA presentan un mejor nivel de escolaridad que el observado en la población general según los resultados del censo 2002, siendo los porcentajes de educación superior o técnica mayores a los registrados por dicha medición.

\begin{tabular}{|c|c|c|c|c|c|c|c|c|c|c|}
\hline \multirow[t]{2}{*}{ Edad } & \multicolumn{2}{|c|}{ 1988-1992 } & \multicolumn{2}{|c|}{ 1993-1997 } & \multicolumn{2}{|c|}{ 1998-2002 } & \multicolumn{2}{|c|}{ 2003-2007 } & \multicolumn{2}{|c|}{ 2008-2012 } \\
\hline & $n$ & Tasa* & $\mathrm{n}$ & Tasa* & $\mathrm{n}$ & Tasa* & $\mathrm{n}$ & Tasa* & $\mathrm{n}$ & Tasa* \\
\hline \multicolumn{11}{|l|}{ SIDA } \\
\hline Pre-escolar & - & - & - & - & - & - & 2 & 0,1 & 7 & 0,2 \\
\hline Básica & 291 & 24,5 & 568 & 26,9 & 709 & 27,7 & 520 & 20,3 & 697 & 16,5 \\
\hline Media & 562 & 47,3 & 993 & 47,1 & 1.135 & 44,3 & 1.087 & 42,4 & 1.570 & 37,1 \\
\hline Superior & 226 & 19,0 & 371 & 17,6 & 436 & 17,0 & 474 & 18,5 & 760 & 18,0 \\
\hline Técnica & - & - & - & - & - & - & 40 & 1,6 & 431 & 10,2 \\
\hline Ninguna & 24 & 2,0 & 49 & 2,3 & 75 & 2,9 & 54 & 2,1 & 59 & 1,4 \\
\hline Desconocido & 84 & 7,1 & 129 & 6,1 & 205 & 8,0 & 385 & 15,0 & 705 & 16,7 \\
\hline Total & 1.187 & 100 & 2.110 & 100 & 2.560 & 100 & 2.562 & 100 & 4.229 & 100 \\
\hline \multicolumn{11}{|l|}{ VIH } \\
\hline Pre-escolar & - & - & - & - & - & - & - & - & 8 & 0,1 \\
\hline Básica & 131 & 22,1 & 389 & 22,7 & 784 & 22,8 & 782 & 18,8 & 684 & 10,9 \\
\hline Media & 257 & 43,4 & 826 & 48,3 & 1.688 & 49,2 & 1.933 & 46,4 & 2.421 & 38,5 \\
\hline Superior & 130 & 22,0 & 346 & 20,2 & 738 & 21,5 & 1.026 & 24,6 & 1.687 & 26,8 \\
\hline Técnica & 0 & - & - & - & - & - & 48 & 1,2 & 854 & 13,6 \\
\hline Ninguna & 5 & 0,8 & 34 & 2,0 & 56 & 1,6 & 60 & 1,4 & 43 & 0,7 \\
\hline Desconocido & 69 & 11,7 & 116 & 6,8 & 168 & 4,9 & 320 & 7,7 & 593 & 9,4 \\
\hline Total & 592 & 100 & 1.711 & 100 & 3.434 & 100 & 4.169 & 100 & 6.290 & 100 \\
\hline
\end{tabular}

Fuente: Formulario caso VIH/SIDA, Depto Epidemiología. MINSAL. *Información preliminar.
En todos los quinquenios las personas en etapa SIDA declaran en su mayoría tener educación media, seguida de educación básica, excepto en el último quinquenio en que la educación superior supera al porcentaje de educación básica. Se observa que en los dos últimos quinquenios, tanto el porcentaje declarado de escolaridad media como el de básica, han disminuido destacando en el último quinquenio que la escolaridad media fue $36,7 \%$, cifra inferior a la mostrada por el Censo 2002 (38\%). Sin embargo, se observa que la educación superior y técnica en el último quinquenio se ve incrementada, representando $28 \%$ del total de casos (Tabla 2).

El mayor porcentaje educacional en todos los quinquenios se concentra en la enseñanza media, seguido en los dos últimos quinquenios por el nivel de educación superior. En general, el nivel educacional de las personas en etapa VIH es superior a las de etapa SIDA, debido a que las personas en etapa VIH concentra sus mayores porcentajes en enseñanza superior y técnica, alcanzando en total $40 \%$ durante el último quinquenio.

En relación al sexo, tanto en hombres como en mujeres, la mayor proporción de personas tuvo enseñanza media en prácticamente todo el período analizado; sin embargo, los hombres tuvieron una mayor proporción de educación superior/técnica que las mujeres. En el último quinquenio los hombres muestran 39\% de educación superior/técnica y las mujeres sólo alcanzan al 17\% (Anexo 5).

Las mujeres declaran un mayor porcentaje de educación básica que los hombres durante todo el período estudiado; sin embargo, en el último quinquenio esta proporción en mujeres se ve disminuida en $24 \%$ entre el cuarto y último quinquenio (Anexo 5).

En las Figuras 8 a y b, se observa cómo en los dos últimos períodos los hombres han aumentado su nivel educacional, incrementando la proporción de educación superior/técnica y disminuyendo la proporción de educación básica y media.

En las mujeres, la educación media se mantiene relativamente estable, aumentando en 56\% la educación superior/técnica entre los últimos dos quinquenios.

Tanto en hombres como en mujeres, el nivel de educación desconocida aumentó marcadamente en los últimos dos quinquenios, lo que implica dificultades o subregistro de esta información en los establecimientos.

\section{Distribución según vía de transmisión}

En Chile, la principal vía de transmisión es la sexual en todos los quinquenios estudiados, representando $99 \%$ en el quinquenio 2008-2012. En el total de casos la vía de exposición mayoritariamente declarada son las prácticas homo/bisexuales, que alcanza a $61 \%$ de los casos notificados en este mismo quinquenio (Tabla 3 ).

La transmisión vertical ha mostrado una notoria disminución en el último quinquenio, alcanzando valores 


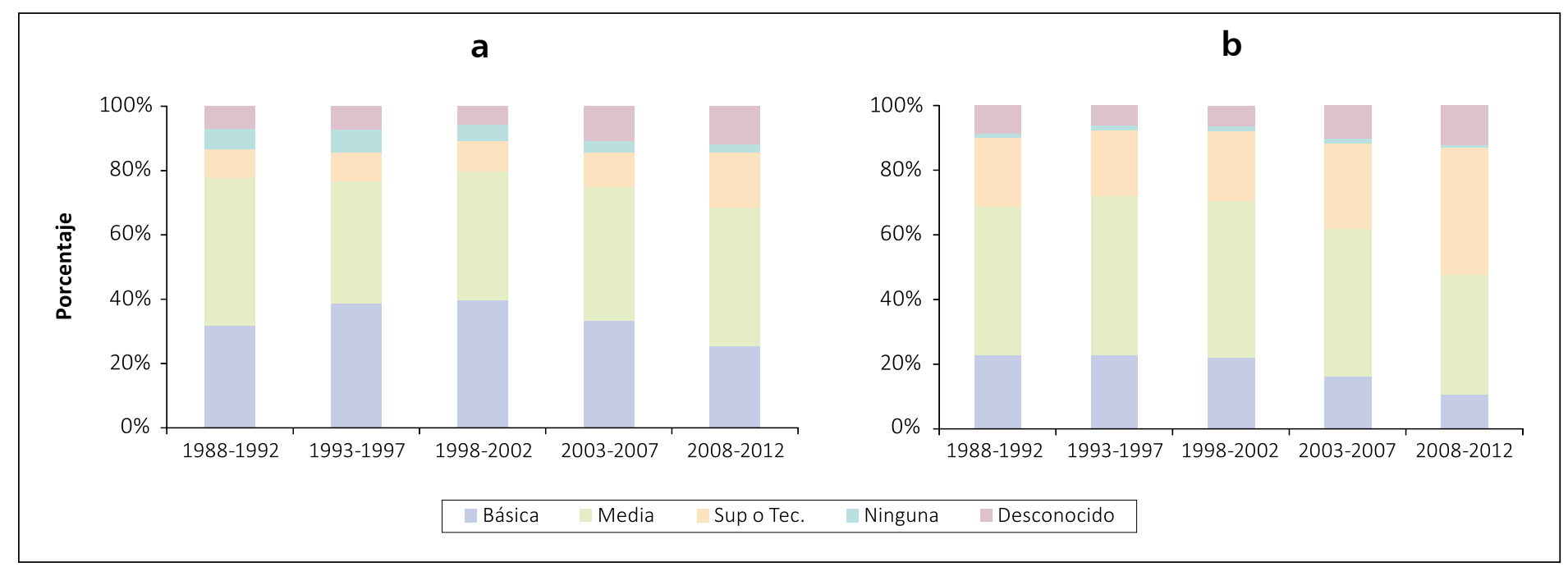

Figura 8. a: Distribución de casos VIH/SIDA, en mujeres, según nivel educacional y quinquenio, Chile 1988-2012*. b: Distribución de casos VIH/SIDA, en hombres, según nivel educacional y quinquenio, Chile 1988-2012*. Fuente: Formulario de notificación VIH/SIDA. Depto. Epidemiología, MINSAL. *Información preliminar.

similares en ambas etapas. La transmisión vertical de VIH es responsable de un bajo porcentaje de las personas notificadas de infección por VIH/SIDA, pero es la causa de la totalidad de los niños afectados por la infección en Chile. Se ha visto una importante reducción de la transmisión por esta vía de exposición, posiblemente explicada por la amplia cobertura y efectividad de las medidas preventivas propuestas por las autoridades de salud.

Se observa que la vía de exposición sanguínea ${ }^{* * * * *}$ ha experimentado un descenso progresivo, llegando a representar sólo $0,2 \%$ del total de las vías de exposición en ambas etapas.

En general, alrededor de $50 \%$ de las personas infectadas por VIH declararon tener sexo entre hombres. Las prácticas heterosexuales en los últimos dos quinquenios se han mantenido relativamente estables, en $40 \%$, mientras que la vía de exposición bisexual ha mostrado una disminución paulatina, representando $9,5 \%$ de las vías de exposición en el último quinquenio.

La distribución de los factores de exposición declarada es muy diferente entre hombres y mujeres, debido a la diferencia de riesgos de adquisición de la infección entre sexos. En etapa SIDA, en el último quinquenio $97 \%$ de las mujeres declaran que la vía heterosexual fue la forma de transmisión del virus, mientras que en hombres, la vía más frecuente son las prácticas de homosexualidad y bisexualidad, que en el último quinquenio representan 63 y $13 \%$, respectivamente (Figuras 9 a y b, Anexo 6).

En etapa SIDA, los hombres muestran un aumento

\begin{tabular}{|c|c|c|c|c|c|c|c|c|c|c|}
\hline \multirow{2}{*}{$\begin{array}{l}\text { Vía de } \\
\text { exposición }\end{array}$} & \multicolumn{2}{|c|}{ 1988-1992 } & \multicolumn{2}{|c|}{ 1993-1997 } & \multicolumn{2}{|c|}{ 1998-2002 } & \multicolumn{2}{|c|}{ 2003-2007 } & \multicolumn{2}{|c|}{ 2008-2012 } \\
\hline & $\mathrm{n}$ & $\%$ & $\mathrm{n}$ & $\%$ & $\mathrm{n}$ & $\%$ & $\mathrm{n}$ & $\%$ & $\mathrm{n}$ & $\%$ \\
\hline Homosexual & 863 & 51,3 & 1.728 & 48,1 & 2.656 & 46,7 & 2.775 & 44,8 & 4.577 & 51,0 \\
\hline Bisexual & 328 & 19,5 & 525 & 14,6 & 754 & 13,2 & 695 & 11,2 & 848 & 9,5 \\
\hline Heterosexual & 354 & 21,1 & 1.095 & 30,5 & 2.098 & 36,9 & 2.612 & 42,2 & 3.473 & 38,7 \\
\hline Vía sanguínea & 116 & 6,9 & 196 & 5,5 & 107 & 1,9 & 34 & 0,5 & 20 & 0,2 \\
\hline Vertical & 20 & 1,2 & 48 & 1,3 & 77 & 1,4 & 72 & 1,2 & 52 & 0,6 \\
\hline Total & 1.681 & 100 & 3.592 & 100 & 5.692 & 100 & 6.188 & 100 & 8.970 & 100 \\
\hline
\end{tabular}

Fuente: Formulario caso VIH/SIDA, Depto Epidemiología. MINSAL. *Información preliminar.

progresivo de la vía de exposición heterosexual como vía de infección, mostrando una relativa estabilización en los últimos dos quinquenios. La práctica homosexual presentó una disminución paulatina hasta el cuarto quinquenio, para luego tener una leve alza hasta representar $50 \%$ de las vías de exposición declaradas. La práctica bisexual experimentó a través de tiempo una disminución gradual (Figura $9 \mathrm{~b}$ ).

En etapa VIH, las mujeres tienen como principal vía de exposición la heterosexual. En los hombres en cambio, la vía de exposición homosexual es la que concentra el mayor porcentaje de casos, representando $69 \%$ en el último quinquenio, con un aumento de $14 \%$ en relación

\footnotetext{
${ }^{* * * * *}$ Se considera como vía sanguínea, la exposición al virus por medio del uso de drogas endovenosas o haber recibido transfusión sanguínea.
} 


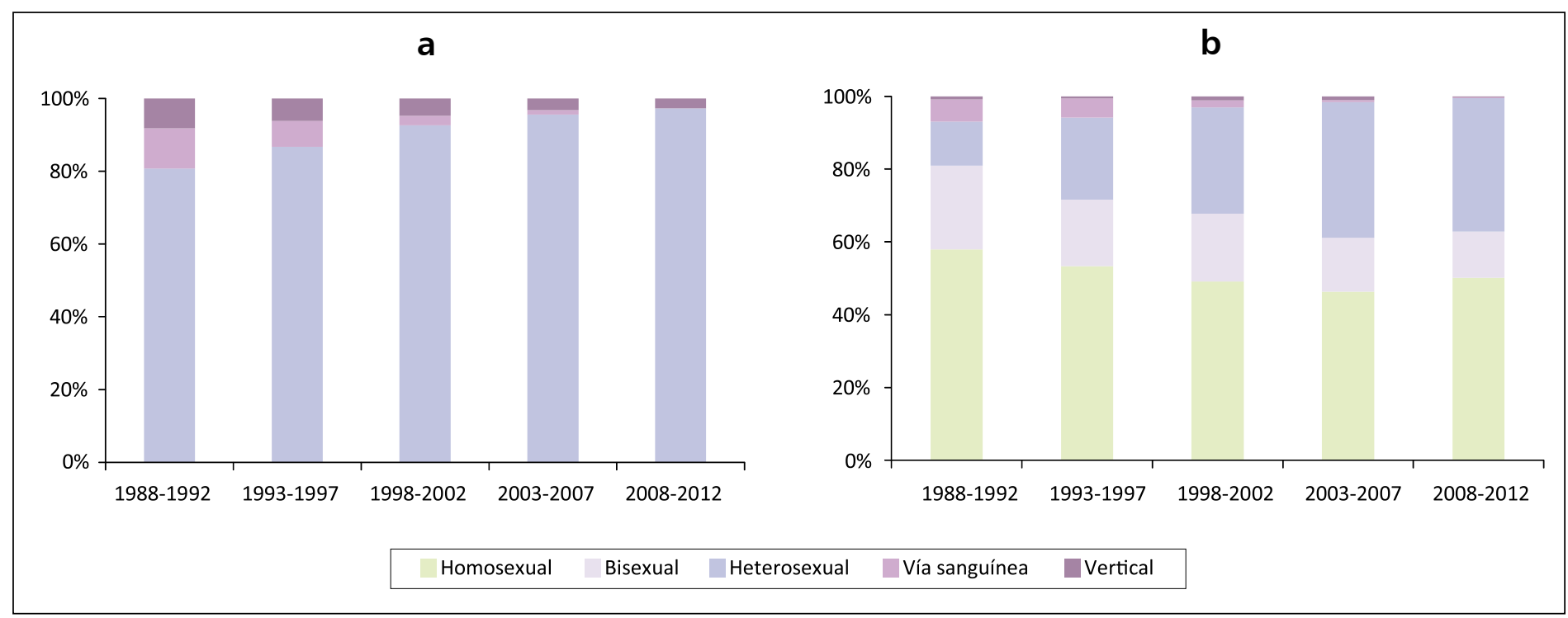

Figura 9. a: Distribución de casos de SIDA en mujeres según factor de exposición y quinquenio. Chile 1988-2012*. b: Distribución de casos de SIDA en hombres según factor de exposición y quinquenio. Chile 1988-2012*. Fuente: Formulario de notificación VIH/SIDA. Depto. Epidemiología, MINSAL. *Información preliminar.

al quinquenio anterior. La vía bisexual ha mostrado una disminución paulatina y la vía de exposición heterosexual muestra una disminución, representando $20 \%$ en el último quinquenio (Figura 10 a y b y Anexo 7).

Se destaca que en etapa SIDA, 63\% de los casos tiene como vía de transmisión las prácticas de homo/ bisexualidad y en etapa VIH este porcentaje aumenta hasta concentrar $80 \%$ de los casos en HSH.

\section{Distribución por etapa diagnóstica en la primera notificación}

Del total de casos de infección por VIH/SIDA notificados en Chile entre 1988 y 2012, 56\% se notificó en etapa VIH mientras que $44 \%$ fue notificado ya en etapa de SIDA.

En hombres y mujeres se observa cómo a través de los quinquenios ha aumentado la proporción de casos notificados en etapa VIH. Desde el segundo quinquenio este porcentaje es superior a los casos notificados en etapa SIDA en mujeres y desde el tercero ocurre esta inversión en hombres (Figuras 11 a y b).

Las mujeres muestran mayores porcentajes de notificación en etapa VIH que los hombres, lo cual puede estar influido por un mayor acceso al examen debido a normativas dirigidas a esta población, como es el control de embarazo lo que permite una detección precoz de la infección. En el último quinquenio, 64\% de las mujeres son notificadas en etapa VIH; sin embargo, es relevante destacar que la proporción de mujeres notificadas en etapa VIH experimenta una disminución de $9 \%$ en relación al quinquenio anterior (Anexo 8).

En los hombres, se observa un ascenso en el porcentaje de detección en etapa VIH, lo que se evidencia a partir del tercer quinquenio donde se produce la inversión de los porcentajes en que la notificación en etapa VIH supera a la etapa SIDA, manteniéndose estable en los últimos dos quinquenios.

La etapa en que se diagnostican las personas es trascendental para el éxito del tratamiento, puesto que a pesar de la efectividad comprobada de las terapias anti-retrovirales y del acceso garantizado a ellas, dicha efectividad está mediada por la oportunidad en su inicio, concentrándose el fracaso terapéutico y la menor sobrevida en las personas que ingresan tardíamente a control y tratamiento.

En el país, en el último quinquenio, $60 \%$ de los casos fue notificado en etapa VIH. Si se analiza geográficamente la distribución según etapas, se observa que las regiones del extremo sur son aquellas en que los casos son notificados tempranamente, seguidas de las regiones de Antofagasta, RM y Los Lagos, a diferencia de las regiones del Libertador B. O'Higgins y Valparaíso, territorio en el cual los casos se notifican en forma tardía, siendo más de $50 \%$ notificados en etapa SIDA (Tabla 4).

\section{Casos notificados que han cambiado a etapa SIDA}

La Circular de Vigilancia Epidemiológica de infección por VIH/SIDA (B51/ 18 del 21 marzo de 2007) incorporó la notificación de los pacientes cuando cambian de etapa diagnóstica VIH a SIDA, lo que se reafirma en la Circular B 51/35 del 14 de octubre de 2010.

Del total de personas notificadas, 593 han cambiado de etapa diagnóstica desde la notificación inicial de etapa VIH a SIDA. 


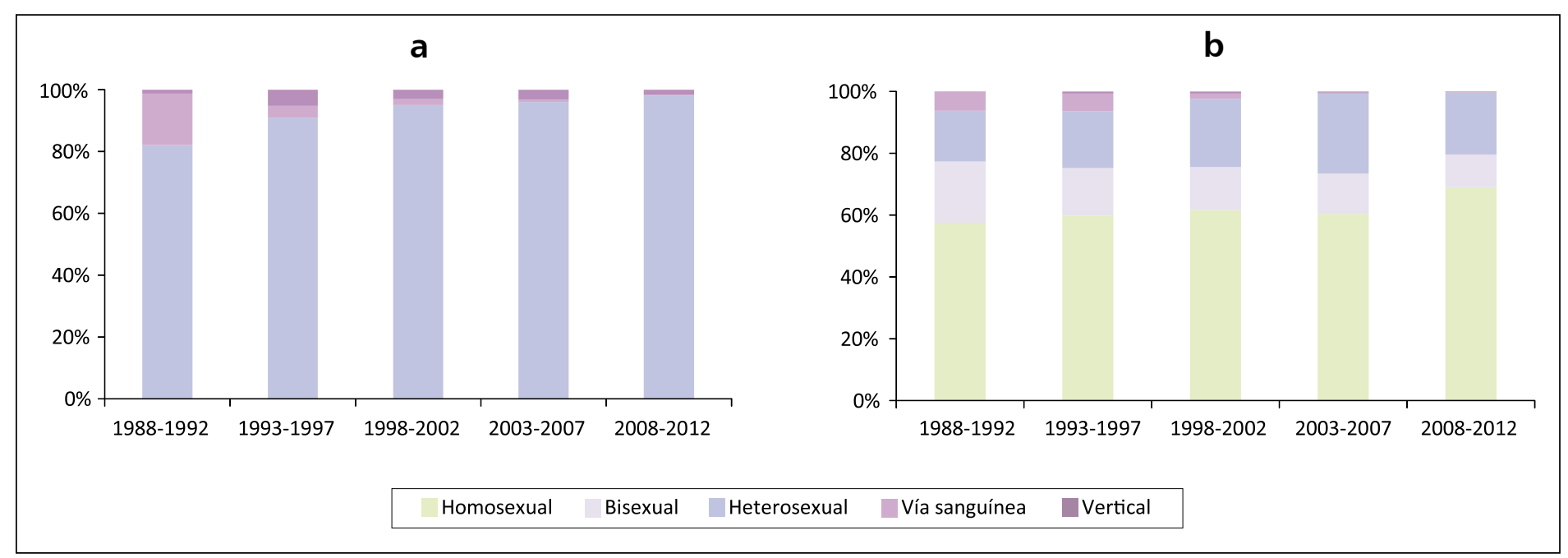

Figura 10. a: Distribución de casos de VIH en mujeres según factor de exposición y quinquenio. Chile 1988-2012*. b: Distribución de casos de VIH en hombres según factor de exposición y quinquenio. Chile 1988-2012*. Fuente: Formulario de notificación VIH/SIDA. Depto. Epidemiología, MINSAL. *Información preliminar.

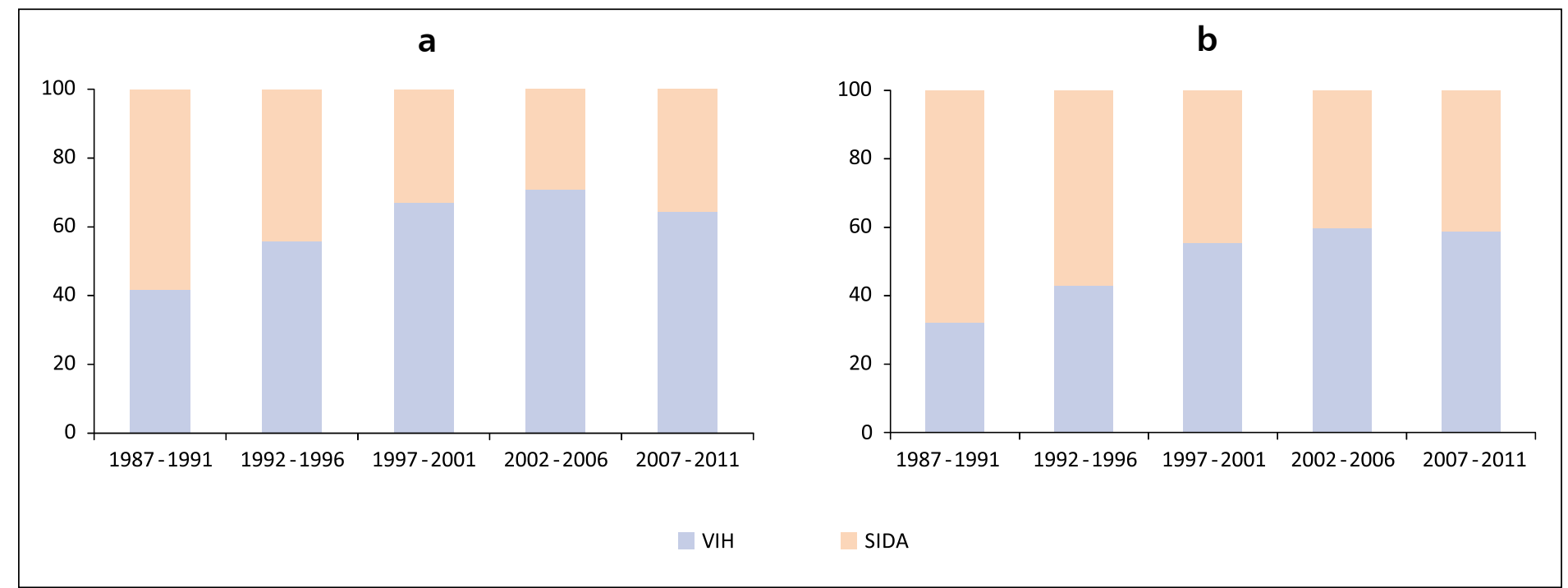

Figura 11. a: Distribución de casos de VIH/SIDA en mujeres por etapa diagnóstica en la $1^{a}$ notificación, Chile 1988-2012*. b: Distribución de casos de VIH/SIDA en hombres por etapa diagnóstica en la $1^{a}$ notificación, Chile 1988-2012*. Fuente: Formulario de notificación VIH/SIDA. Depto. Epidemiología, MINSAL. *Información preliminar.

Al analizar la información por rangos de tiempo, se observa que $46 \%$ de las personas cambió de etapa diagnóstica durante los primeros tres años desde la notificación del caso, mientras que casi $25 \%$ lo hizo entre 4 y 6 años post diagnóstico y sólo $12 \%$ cambió de etapa diagnóstica después de 10 años o más desde la notificación inicial (Figura 12).

Esta situación torna más complejo el pronóstico de las personas afectadas, puesto que a una gran proporción de personas con diagnóstico inicial de enfermedad avanzada se suma el cambio de etapa VIH a SIDA en un tiempo breve, lo que releva el desafío iniciado por el Ministerio de Salud de implementar estrategias que promuevan el diagnóstico precoz de la infección por VIH, para lograr el adecuado impacto del tratamiento anti-retroviral.

\section{Otras variables de caracterización}

\section{Nacionalidad de las personas notificadas}

Durante los últimos tres quinquenios, $98 \%$ de los casos notificados correspondieron a personas chilenas. En el período 2008-2012 el número de extranjeros notificados fue de 259 personas. De ellos, $86 \%$ provino de América 


\begin{tabular}{|c|c|c|c|c|c|c|c|c|c|c|}
\hline \multirow[t]{2}{*}{ Región } & \multicolumn{2}{|c|}{ 1988-1992 } & \multicolumn{2}{|c|}{ 1993-1997 } & \multicolumn{2}{|c|}{ 1998-2002 } & \multicolumn{2}{|c|}{ 2003-2007 } & \multicolumn{2}{|c|}{ 2008-2012 } \\
\hline & $\mathrm{n}$ & $\%$ & $\mathrm{n}$ & $\%$ & $\mathrm{n}$ & $\%$ & $\mathrm{n}$ & $\%$ & $\mathrm{n}$ & $\%$ \\
\hline \multicolumn{11}{|l|}{ SIDA } \\
\hline Arica y Parinacota & 8 & 44,4 & 36 & 49,3 & 67 & 45,0 & 80 & 41,5 & 130 & 42,1 \\
\hline Tarapacá & 11 & 68,8 & 11 & 50,0 & 81 & 49,4 & 66 & 36,5 & 121 & 43,8 \\
\hline Antofagasta & 23 & 74,2 & 54 & 62,8 & 80 & 35,9 & 82 & 30,3 & 126 & 33,2 \\
\hline Atacama & 1 & 33,3 & 9 & 64,3 & 12 & 30,0 & 38 & 39,2 & 79 & 47,3 \\
\hline Coquimbo & 16 & 64,0 & 27 & 42,9 & 71 & 37,0 & 82 & 36,4 & 168 & 44,1 \\
\hline Valparaíso & 201 & 69,8 & 269 & 51,2 & 326 & 41,4 & 316 & 42,2 & 558 & 50,8 \\
\hline Metropolitana & 843 & 65,8 & 1.453 & 55,4 & 1.445 & 42,2 & 1.301 & 37,9 & 1.929 & 36,3 \\
\hline O'Higgins & 6 & 37,5 & 31 & 50,0 & 40 & 36,4 & 80 & 35,7 & 154 & 52,4 \\
\hline Maule & 15 & 62,5 & 45 & 55,6 & 97 & 48,5 & 87 & 36,9 & 144 & 47,2 \\
\hline Bío-Bío & 38 & 86,4 & 92 & 64,8 & 195 & 56,9 & 234 & 42,7 & 369 & 43,0 \\
\hline Araucanía & 5 & 100,0 & 22 & 64,7 & 71 & 47,0 & 73 & 46,2 & 162 & 49,5 \\
\hline Los Ríos & 7 & 77,8 & 24 & 75,0 & 22 & 56,4 & 35 & 31,5 & 77 & 41,0 \\
\hline Los Lagos & 11 & 73,3 & 25 & 64,1 & 38 & 27,1 & 76 & 30,0 & 195 & 37,1 \\
\hline Aisén & 0 & - & 3 & 50,0 & 8 & 50,0 & 3 & 15,8 & 3 & 9,1 \\
\hline Magallanes & 2 & 66,7 & 9 & 50,0 & 7 & 41,2 & 9 & 29,0 & 14 & 23,7 \\
\hline Total & 1.187 & 66,7 & 2.110 & 55,2 & 2.560 & 42,7 & 2.562 & 38,1 & 4.229 & 40,2 \\
\hline \multicolumn{11}{|l|}{ VIH } \\
\hline Arica y Parinacota & 10 & 55,6 & 37 & 50,7 & 82 & 55,0 & 113 & 58,5 & 179 & 57,9 \\
\hline Tarapacá & 5 & 31,3 & 11 & 50,0 & 83 & 50,6 & 115 & 63,5 & 155 & 56,2 \\
\hline Antofagasta & 8 & 25,8 & 32 & 37,2 & 143 & 64,1 & 189 & 69,7 & 254 & 66,8 \\
\hline Atacama & 2 & 66,7 & 5 & 35,7 & 28 & 70,0 & 59 & 60,8 & 88 & 52,7 \\
\hline Coquimbo & 9 & 36,0 & 36 & 57,1 & 121 & 63,0 & 143 & 63,6 & 213 & 55,9 \\
\hline Valparaíso & 87 & 30,2 & 256 & 48,8 & 462 & 58,6 & 432 & 57,8 & 540 & 49,2 \\
\hline Metropolitana & 439 & 34,2 & 1.171 & 44,6 & 1.977 & 57,8 & 2.135 & 62,1 & 3.388 & 63,7 \\
\hline O’Higgins & 10 & 62,5 & 31 & 50,0 & 70 & 63,6 & 144 & 64,3 & 140 & 47,6 \\
\hline Maule & 9 & 37,5 & 36 & 44,4 & 103 & 51,5 & 149 & 63,1 & 161 & 52,8 \\
\hline Bío-Bío & 6 & 13,6 & 50 & 35,2 & 148 & 43,1 & 314 & 57,3 & 490 & 57,0 \\
\hline Araucanía & 0 & 0,0 & 12 & 35,3 & 80 & 53,0 & 85 & 53,8 & 165 & 50,5 \\
\hline Los Ríos & 2 & 22,2 & 8 & 25,0 & 17 & 43,6 & 76 & 68,5 & 111 & 59,0 \\
\hline Los Lagos & 4 & 26,7 & 14 & 35,9 & 102 & 72,9 & 177 & 70,0 & 331 & 62,9 \\
\hline Aisén & 0 & - & 3 & 50,0 & 8 & 50,0 & 16 & 84,2 & 30 & 90,9 \\
\hline Magallanes & 1 & 33,3 & 9 & 50,0 & 10 & 58,8 & 22 & 71,0 & 45 & 76,3 \\
\hline Total & 592 & 33,3 & 1.711 & 44,8 & 3.434 & 57,3 & 4.169 & 61,9 & 6.290 & 59,8 \\
\hline
\end{tabular}

Fuente: Formulario caso VIH/SIDA, Depto Epidemiología. MINSAL. *Información preliminar.

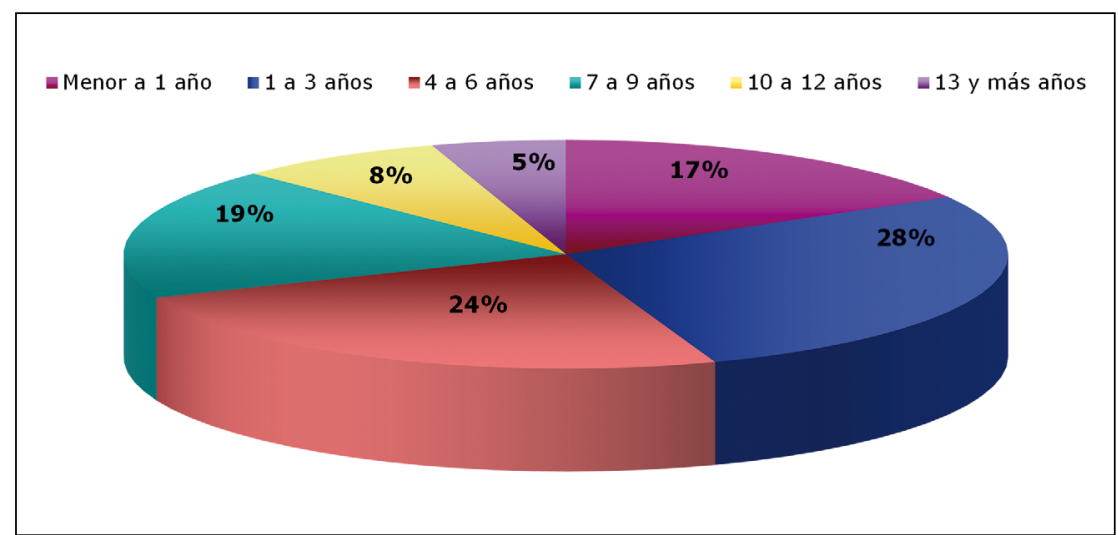

Figura 12. Porcentaje de casos notificados que cambiaron de etapa VIH a SIDA, por rango de tiempo, Chile 1984-2012*. Fuente: Formulario de notificación VIH/SIDA. Depto. Epidemiología, MINSAL. *Información preliminar. del Sur, seguido de $7 \%$ de personas de origen centroamericano (Mapa 3).

Al realizar un análisis de las personas notificadas como extranjeras se observa que a lo largo del tiempo, el número de casos ha ido en aumento. De acuerdo a su país de origen, los casos notificados durante el último quinquenio corresponden en su mayoría a personas de nacionalidad peruana $(46 \%)$, colombiana $(14 \%)$ y argentina $(11 \%)$ (Figura 13).

Se destaca que en el último quinquenio, las personas de nacionalidad colombiana y boliviana han experimentado los mayores aumentos porcentuales en relación al quinquenio anterior (61 y 53\%, respectivamente). Si bien la mayor parte de los casos en extranjeros se concentra en personas de Perú, las cuales han aumentado en términos de números absolutos, en relación al total de extranjeros muestran una disminución de $22 \%$ en comparación con el quinquenio anterior.

Según distribución geográfica, las regiones del extremo norte del país muestran los mayores porcentajes de personas extranjeras, siendo la Región de Tarapacá la que concentra $10 \%$ de sus casos en personas de otros países, seguidas de Arica y Parinacota y Antofagasta, donde ambas regiones presentan $6 \%$ de las personas notificadas como extranjeras. En el último quinquenio, la Región de Magallanes y Aysén suben el porcentaje de casos en extranjeros, llegando a representar 3\% del total. Se destaca que la Región del Libertador B. O'Higgins es la única en la que durante los tres quinquenios no ha presentado casos en personas extranjeras.

Lo anterior, probablemente responde el gran intercambio fronterizo presente en las regiones limítrofes, debido a múltiples factores como la búsqueda de fuentes laborales que ofrece el país, la facilidad de acceso a la atención y a la garantía estatal del tratamiento anti-retroviral, generando una alta presencia de poblaciones móviles que establecen dinámicas temporales situación que aumenta su vulnerabilidad y riesgo de transmisión/adquisición del VIH y otras ITS.

Es importante resaltar que, si bien en las regiones del norte del país existe una mayor proporción de casos notificados como casos de infección por VIH en población extranjera, estos porcentajes por sí solos no explican las altas tasas de infección por VIH/SIDA que muestran estas regiones, las que se incrementan debido al aumento de casos en personas de nacionalidad chilena.

\section{Conductas sexuales declaradas}

\section{Número de parejas sexuales}

De acuerdo a la declaración del número de parejas sexuales durante los últimos 12 meses (previos a la notificación) en el último quinquenio, $48 \%$ de los casos de infección por VIH/SIDA tienen una pareja sexual, 


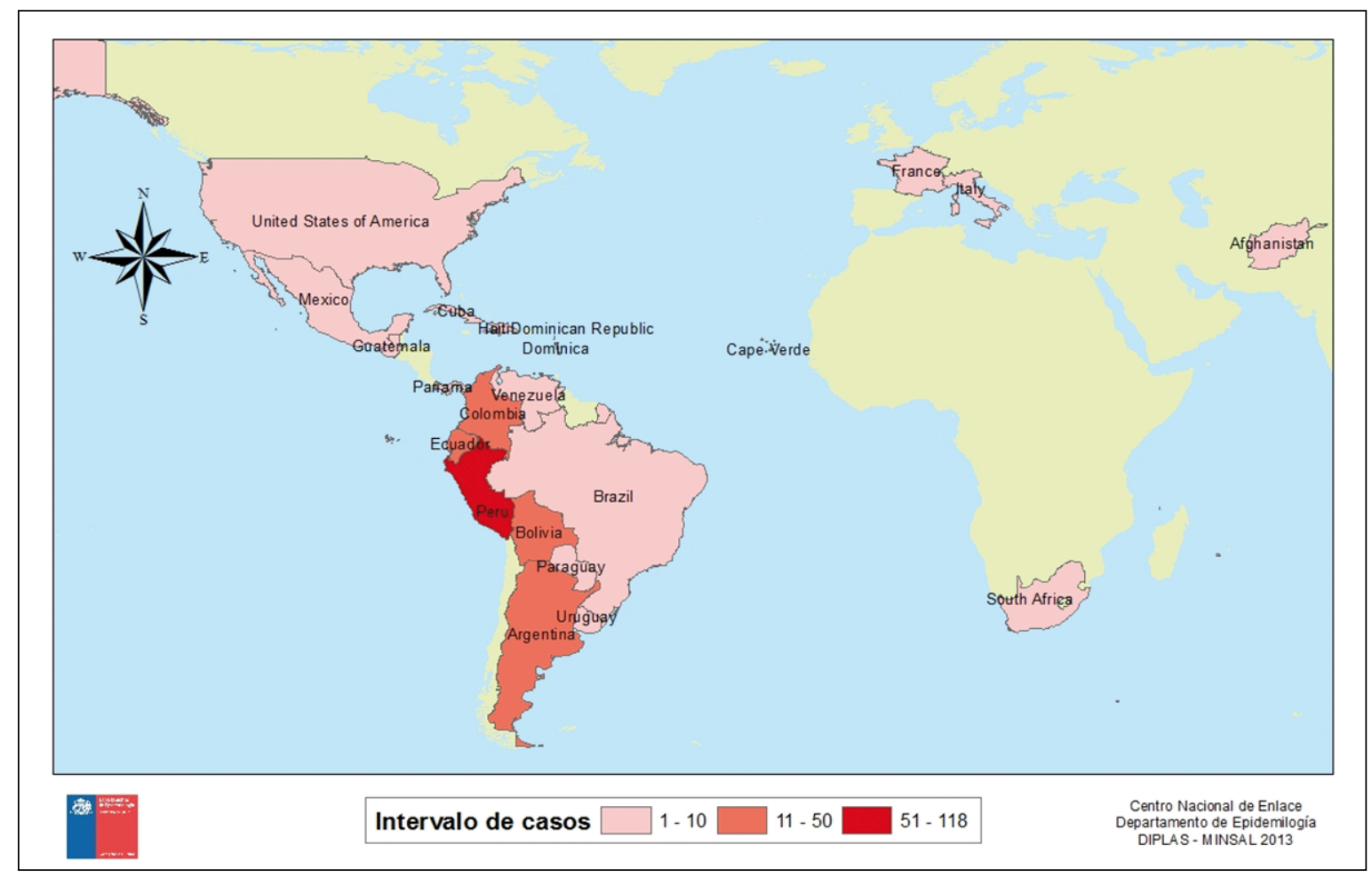

Mapa 3. Casos de infección por $\mathrm{VIH} / \mathrm{SIDA}$ en extranjeros notificados en Chile, según país de origen, 2008-2012.

mientras que $42 \%$ declara haber tenido dos o más parejas en el mismo período.

De acuerdo al sexo, el número de parejas sexuales declaradas durante los últimos 12 meses muestra que 70\% de las mujeres tienen pareja sexual exclusiva, mientras que en los hombres esta opción sólo representa el 43\%. El $46 \%$ de los hombres tiene dos o más parejas sexuales (Figura 14).

\section{Uso de preservativo}

En relación al uso del preservativo en personas que declaran tener pareja en los últimos 12 meses, 53\% declara usarlo "a veces", $36 \%$ no lo usa "nunca" y sólo $11 \%$ lo utiliza "siempre".

Según el análisis del número de parejas de acuerdo al uso de condón, se evidencia que los casos con pareja sexual única son quienes declaran el menor porcentaje de uso de condón, dado que la opción "nunca" concentra el $47 \%$. Esto indicaría una baja percepción de riesgo, que resulta relevante considerando que son personas que probablemente adquirieron el VIH según lo declarado, en una relación de pareja exclusiva e implica la necesaria profundización de las estrategias preventivas (Figura 15).

Se observa que, independiente del número de parejas sexuales, el uso del preservativo "siempre" presenta bajos porcentajes de declaración, siendo de alrededor de $10 \%$. Por su parte, las personas con 5 o más parejas sexuales,

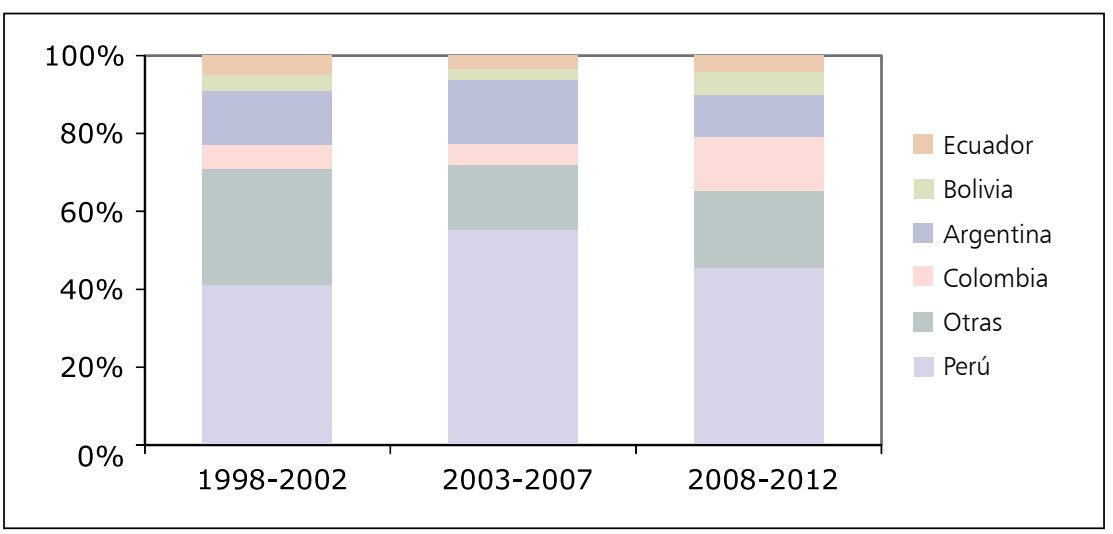

Figura 13. Porcentaje de casos de infección por VIH/SIDA, según nacionalidad y quinquenio. Chile, 1998-2012*. Fuente: Formulario de notificación VIH/SIDA. Depto. Epidemiología, MINSAL. *Información preliminar.

las que podrían considerarse de mayor riesgo, concentran alrededor de $70 \%$ de uso de condón "a veces" y $19 \%$ no lo usa "nunca".

De acuerdo a las conductas sexuales, de las personas que declaran ser heterosexuales, 59\% "nunca" usa preservativo, $35 \%$ lo utiliza "a veces" y sólo $6 \%$ lo usa "siempre". De los hombres que tienen sexo con hombres, $13 \%$ utiliza siempre el preservativo, $66 \%$ lo usa "a veces" y 21\% "nunca" (Figura 15).

Según se muestra en la Figura 16, al analizar la perio- 
Figura 14. Distribución de casos de VIH/SIDA, según número de parejas sexuales declaradas durante los últimos 12 meses y sexo. Chile 20082012*. Fuente: Formulario de notificación VIH/SIDA. Depto. Epidemiología, MINSAL. *Información preliminar.

Figura 15. Distribución de casos de VIH/SIDA, según número de parejas sexuales en los últimos 12 meses y uso de condón. Chile 20082012*. Fuente: Formulario de notificación VIH/SIDA. Depto. Epidemiología, MINSAL. *Información preliminar.

Figura 16. Distribución de casos de VIH/SIDA, según uso de preservativo en los últimos 12 meses. Chile 20082012*. Fuente: Formulario de notificación VIH/SIDA. Depto. Epidemiología, MINSAL. *Información preliminar.
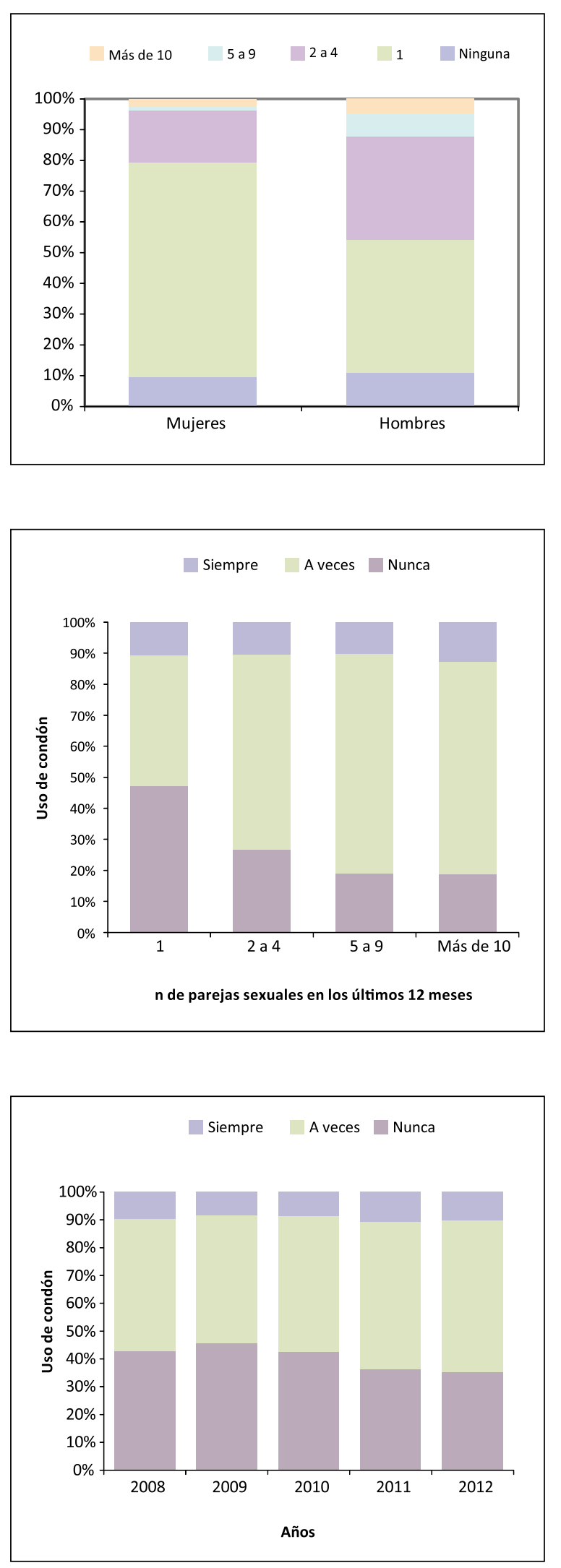

dicidad del uso de preservativo a través de los años, se evidencia que no se ha producido un cambio en el comportamiento, dado que el uso consistente del preservativo se ha mantenido estable alrededor de $10 \%$ desde el año 2008 al 2012. En el uso esporádico tampoco se muestran grandes cambios en el porcentaje de utilización.

El bajo uso de preservativo "siempre" no presenta grandes diferencias porcentuales entre las personas que declaran como conducta sexual ser heterosexuales, homosexuales o bisexuales, siendo un tema transversal a las personas notificadas en el último quinquenio. Esto sumado a que a través del tiempo no se evidencia un aumento en el uso consistente del preservativo, implica un riesgo en la adquisición del virus, dado que su uso esporádico (a veces) no se considera una forma de protección real, significando un riesgo similar al no uso.

\section{Mortalidad por SIDA Chile 1990-2011}

A partir del año 1990, se registran las primeras defunciones a causa de SIDA. Entre 1990 y 2011 se produjeron en Chile 7.842 defunciones por SIDA, de las cuales $87 \%$ (6.814) corresponden a hombres. Las defunciones por SIDA desde el año 2002 en adelante representan entre $0,4 \%$ y $0,5 \%$ del total de defunciones ocurridas en el país.

La tasa de mortalidad experimentó un aumento progresivo hasta el 2001, año en que se observó la tasa más alta del período (3,6 por cien mil habs.). En los últimos nueve años (2002-2011), la mortalidad por SIDA ha mostrado una relativa estabilización con algunas fluctuaciones llegando el 2011 a 2,7 por cien mil habs (Anexo 9).

La tendencia estacionara en la curva de mortalidad puede atribuirse al impacto de la terapia anti-retroviral, cuya eficacia ha ido en aumento en los últimos años, observándose un incremento de los niveles de linfocitos T CD4+ y disminución de la carga viral. La estabilización de la mortalidad observada es coherente con el estudio de evaluación del impacto del tratamiento anti-retroviral ${ }^{9} \mathrm{en}$ el que se ha verificado un aumento de la sobrevida de las personas con terapia a tres años de seguimiento, desde $85 \%$ en 2005 a $96,5 \%$ en 2011 , concentrándose la muerte en personas con inicio de tratamiento en etapa avanzada de deterioro clínico e inmunológico.

Entre los años 2001 y 2011 los hombres disminuyeron la tasa de mortalidad de 6,2 a 4,5 por cien mil habs. Sin embargo, en el último quinquenio la tasa se ha mantenido estable, experimentando mínimas fluctuaciones. Las mujeres desde el año 2002 presentan tasas que se han mantenido estables entre 0,6 a 0,8 por cien mil habs, subiendo levemente el 2011 a 1,1 por cien mil habs. (Figura 17).

A partir de 1998 se observa un descenso progresivo de la razón de mortalidad hombre/mujer, excepto el año 2004 en que esta razón experimenta un aumento, siendo 
de 8,3 hombres por cada mujer. Desde el año 2005, esta razón tiende a mantenerse estable, sólo con un aumento puntual en el 2007, dado por la disminución en la tasa de mortalidad de las mujeres. El año 2011 se observa una disminución siendo la razón de mortalidad hombre/mujer de 4,5, debido al aumento de la mortalidad en mujeres.

Durante el último quinquenio, el grupo de 30 a 59 años concentra alrededor de 76 a $78 \%$ del total de las defunciones por SIDA. Según se observa en la Figura 18 , los grupos de 30 a 39 y 40 a 49 años presentan las tasas más elevadas de mortalidad por SIDA, llegando a presentar valores iguales en el año 2011 con una tasa de 5,9 por cien mil habs. Los demás grupos de edad muestran una relativa estabilización de sus tasas. Los pacientes bajo 10 años de edad sólo representan entre 0,5 y $1,6 \%$ del total de defunciones durante el período, alcanzando una tasa de 0,1 por cien mil habs. en el año 2011 (Anexo 10).

En el período estudiado la mayor tasa de mortalidad observada en los hombres se presenta entre los 30 a 39 y 40 a 49 años alcanzando ambos grupos igual tasa el año 2011 (9,7 por cien mil habs.). El grupo de 50 a 59 años presenta un leve aumento de sus tasas, con una estabilización en los últimos tres años. En las mujeres en tanto, existe un aumento sostenido de la tasa en el grupo de 40 a 49 años cuyo valor en el último año alcanza al grupo de 30 a 39 años, mostrando el mismo comportamiento observado en los hombres. En los demás tramos de edad existe una relativa estabilización de las tasas (Anexo 10).

En el último quinquenio, las causas específicas de mortalidad por SIDA muestran que las defunciones resultantes en enfermedades infecciosas y parasitarias se han mantenido estables representando alrededor $50 \% \mathrm{del}$ total. Se observa además un aumento de las defunciones resultantes en tumores malignos y una disminución en las sin especificación, lo que demuestra que ha mejorado el diagnóstico específico de defunción a causa de SIDA. En el año 2011, 49,4\% de las defunciones por SIDA correspondieron a causas resultantes en enfermedades infecciosas y parasitarias y $15,7 \%$ a enfermedades resultantes en tumores malignos (Figura 19).

Según distribución geográfica, en los últimos cinco años la mortalidad por SIDA se concentra en las regiones del norte del país, destacándose la Región de Arica y Parinacota, la que muestra en todo el quinquenio una de la tasas más elevada de la nación, llegando el 2011 a 7,6 por cien mil habs., situación coincidente con las elevadas tasas de infección por VIH/SIDA que se presentan en esta región, seguida de la Región de Tarapacá con tasas que para este mismo año alcanzan 4,7 muertes por cien mil habs. (Anexo 11).

En general, en todas las regiones de Chile se ha producido un aumento de las tasa de mortalidad por SIDA, presentándose algunas fluctuaciones entre los años de estudio.

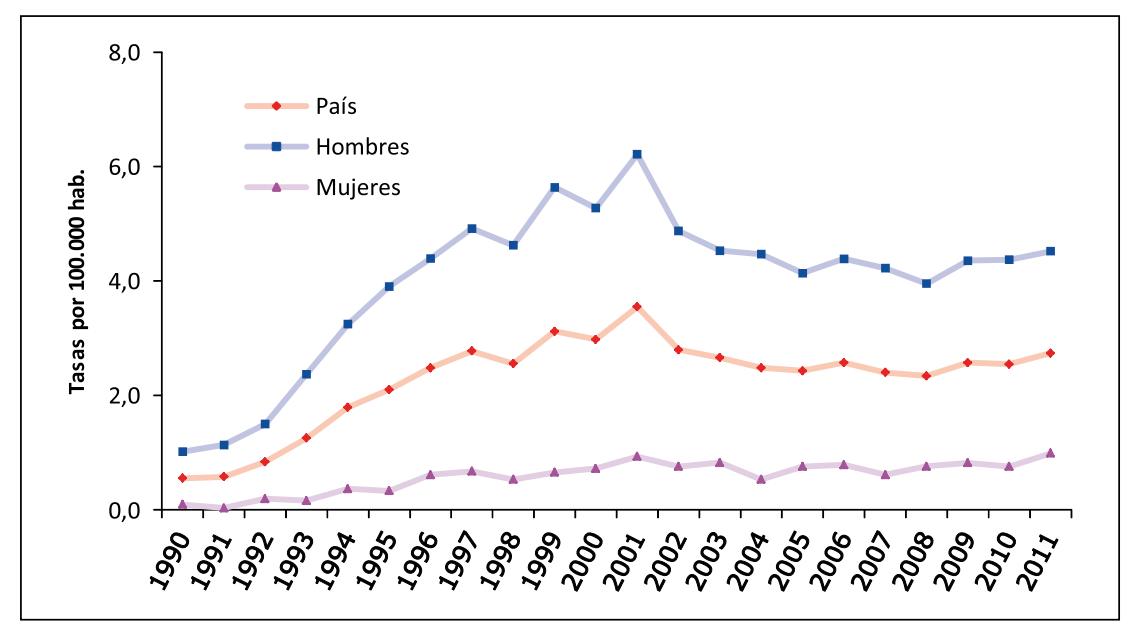

Figura 17. Mortalidad por SIDA, según sexo, Chile 1990-2011. Fuente: Base defunciones, DEIS, MINSAL.

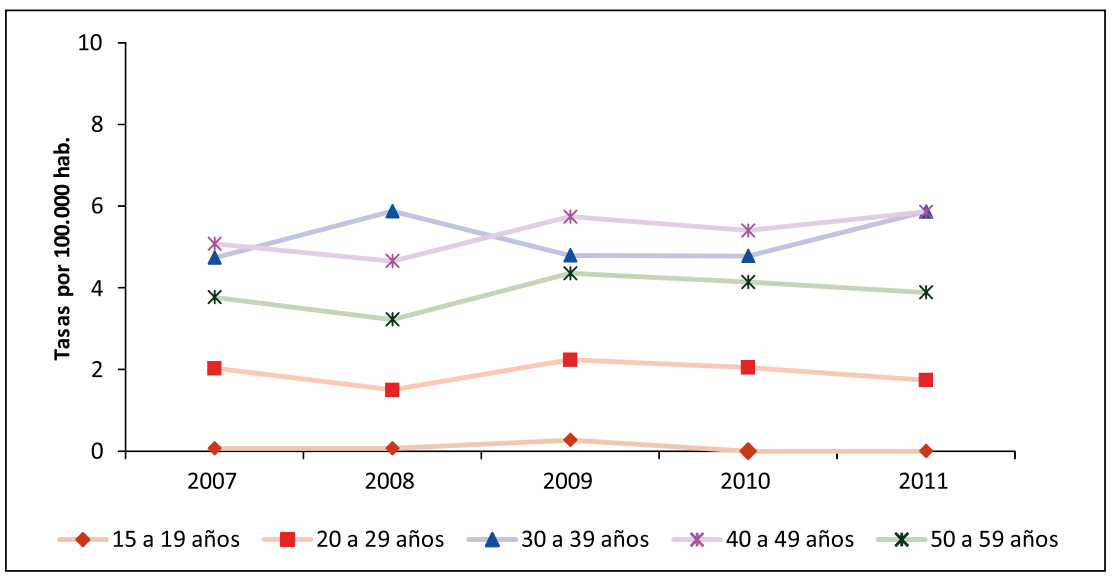

Figura 18. Tasa de mortalidad por SIDA según grupos de edad. Chile 2007-2011. Fuente: Base defunciones, DEIS, MINSAL.

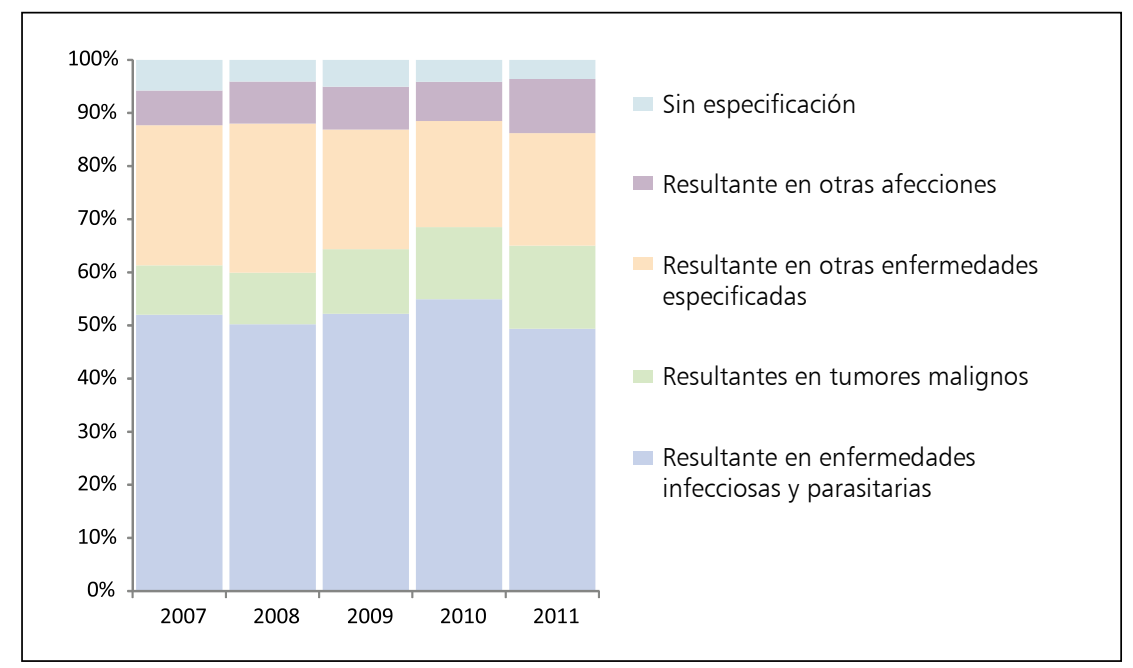

Figura 19. Causas específicas de mortalidad por SIDA. Chile 2007-2011. Fuente: Base defunciones, DEIS, MINSAL. 
Mapa 4. Tasa de mortalidad por SIDA según regiones. Chile, 2007-2011.

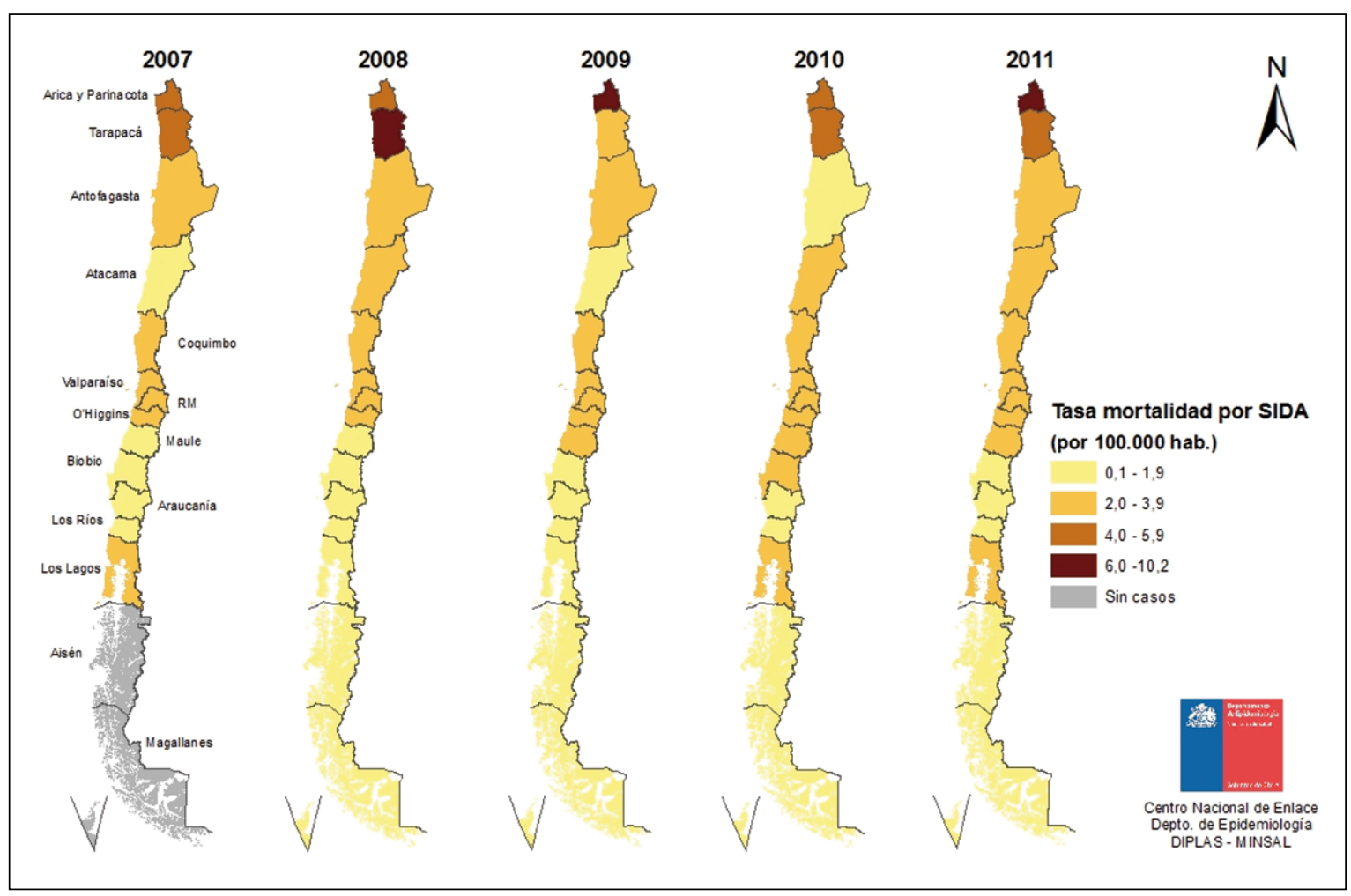

Desde el año 2009 las regiones desde Maule al norte presentan tasas superiores a la nacional y las regiones con la menor mortalidad se encuentran en el sur del país desde Bío-Bío a Magallanes, siendo Los Ríos y La Araucanía las regiones con las menores tasas en este período.

En el resto del país las tasas de mortalidad por SIDA se encuentran por debajo de 4 por cien mil habs., concentrándose principalmente en la zona centro norte del país (Mapa 4).

\section{Análisis de los determinantes sociales de la salud}

\section{Educación sexual y medios de comunicación}

El informe país 2012 de infección por VIH/SIDA presenta en sus resultados la categorización de años de escolaridad como factor de análisis. A partir de estos datos, es preciso exponer que la escolarización y el sistema de educación, en general son parte fundamental de la construcción de normas y regulación de las políticas de prevención de la población escolar en particular, y en gran medida ejecutor a partir de los sistemas de comunicaciones existentes en el país.

Los medios de comunicación masivos se han convertido en un puente entre la población y la información con respecto de la infección por VIH/SIDA y su transmisión. El fenómeno de las redes sociales es un nuevo foco de estudio desde los determinantes sociales, y específicamente en la educación de los adolescentes. A través de estos sistemas, las comunicaciones se hacen más directas sobre los flujos de información hacia la interconectividad de las personas, especialmente de los adolescentes y jóvenes que potencialmente establecerían relaciones sociales y amorosas. Igualmente como medio de información estas plataformas se convierten en conductos de propagación de estilos de vidas y formación de relaciones virtuales.

Esta temática busca generar un debate a partir de la participación y rol que tienen los medios de comunicación en la educación y prevención de ITS, de cómo las políticas públicas han sido orientadas a que los medios sean un canal de prevención en la salud sexual de la población chilena con distintas campañas publicitarias.

Según la encuesta nacional de la INJUV de 2012, $52,7 \%$ de los jóvenes encuestados de 20 o menos años se declaró iniciado sexualmente. La diferencia entre hombres y mujeres se estrecha según el sondeo, por lo que la variación porcentual no es significativa (73-70\%) a diferencia de la medición del año 2006, que contaba con una diferencia significativa de 6 puntos entre hombres $(75 \%)$ y mujeres $(69 \%)^{10}$.

El $66,6 \%$ de jóvenes de 25 años se declara iniciado 
sexualmente. Respecto a nivel socio-económico, el grupo E declara una iniciación sexual de $63 \%$ entre 15 y 19 años, convirtiéndose en el grupo de mayor vulnerabilidad del estudio.

En relación al uso de preservativos se señala que $81 \%$ lo utilizó en su última relación sexual (lo que indica uso consistente), para la prevención del embarazo, $56,6 \%$ para prevenir el VIH y 54,4\% para prevenir otras ITS.

La utilización del condón en la última relación sexual para prevenir la infección por VIH/SIDA arrojó un 59\% en los hombres y $37 \%$ en las mujeres, en el año 2012, señalando una inequidad de género, que genera un mayor riesgo a las mujeres versus los hombres. A pesar de lo anterior, el uso del condón se incrementó respecto a 2009 evidenciándose $40 \%$ de utilización. Se puede inferir que la población juvenil ha desarrollado un pequeño cambio conductual respecto a las ITS, donde las campañas de difusión han potenciado el escenario actual.

Como dato relevante se señala que $26 \%$ de la población juvenil al menos se ha hecho alguna vez en su vida el test de ELISA.

Se puede que plantear que el tabú respecto a las ITS ha ido declinando dentro de las conductas de los jóvenes, pero aún es fundamental explicar que los adolescentes tienen como preferencia su uso para prevenir el embarazo, dejando como segunda prioridad su utilización en la prevención de la infección por VIH/SIDA u otras ITS. Esta situación pone un desafío a las políticas públicas tanto educacionales como de salud en la promoción y enseñanza del uso del preservativo en los adolescentes y jóvenes, especialmente considerando las cifras de infección por VIH señaladas anteriormente. Algunas teorías apuntan a la naturalización de la enfermedad, es decir, que se aprecia un bajo riesgo en la transmisión de una ITS v/s el embarazo adolescente, pues existe la visión que el país cubre las necesidades de tratamiento mediante el GES, tratamiento que dado su alto impacto, disminuiría las probabilidades de muerte transformando a la infección por VIH/SIDA en una enfermedad crónica.

\section{Inmigración y pueblos originarios}

La inmigración es un factor estructural asociado a infecciones por VIH/SIDA como determinante de vulnerabilidad, a partir de la dificultad que se da en el acceso a la atención oportuna, al desconocimiento del funcionamiento del sistema de salud del país, y en gran medida a las dificultadas sociales propias de una sociedad desconocida; normas, leyes, sistemas de valores y culturales. El vínculo entre migración y contagio de VIH/SIDA está asociado a factores normativos de conductas personales y del medio social; mantener relaciones sexuales sin protección, el comercio sexual, la discriminación y marginación del sistema de salud.

Es preciso hacer hincapié que no existe una relación directa entre migraciones y contagios de ITS, sino factores asociados a la vulnerabilidad (educación, acceso, pobreza, etc.) que la población inmigrante desarrolla al momento de asentarse en el país ${ }^{11}$.

En el caso de los pueblos originarios determinan la sectorización de etnias al interior del país. El lenguaje, la medicina alternativa, la ruralidad y la incidencia de la tradición y cultura son factores asociados a riesgos que podrían posibilitan el contraer el virus. El obtener asistencia a una atención pertinente y oportuna es fundamental.

\section{Género}

Este tópico está abordado desde la categorización de una conducta en particular, que no necesariamente puede ser prolongada en el tiempo, es decir, que la población (heterosexual, bisexual, homosexual, etc.), establece relaciones de pareja a corto, medio y largo plazo.

Las conductas y orientaciones sexuales se relacionan a partir de la formación de estilos de vida de las personas, dependiendo de las interacciones y símbolos sociales propios de los individuos que desarrollan y manifiestan al interior de la sociedad.

La encuesta realizada por INJUV en el año 2012, mide la orientación sexual declarada de la población juvenil entre 15 y 29 años. El 84\% de los encuestados dice tener una orientación heterosexual, $2 \%$ declara ser homosexual y $1 \%$ bisexual ( $13 \%$ optó por no contestar esta pregunta).

Como es sabido, la auto declaración de la condición sexual está condicionada por las características culturales, especialmente aquellas vinculadas a los niveles de discriminación imperantes o presentes en una comunidad determinada. Frente al riesgo de infección por VIH y otras ITS, lo relevante es la conducta y/o las prácticas sexuales.

Los grupos de riesgo siguen estando en $\mathrm{HSH}$, ya sea por estilos de vida y conductas sexuales; sin embargo, el reporte del año 2012 expone un alza en las tasas de notificaciones de mujeres, con pareja única en muchos casos.

A partir de este dato, surge la necesidad de establecer cómo en definitiva se están contagiando y qué impacto social se está dando mediante esta situación.

El concepto de feminización de la epidemia (OPS, 2012), particularmente en América Latina, ha surgido mediante la transmisión del virus por el género masculino, donde en numerosos casos el control tiene como resultado el diagnóstico tardío en etapa SIDA en mujeres.

Las inequidades de género en estos casos están vinculadas a partir del impacto específico y directo sobre las mujeres en la sociedad, donde pasan a transformarse en parte de los grupos vulnerables.

El sexo sin protección por contar con pareja única, el comercio sexual, la discriminación y el tardío diagnóstico son factores a estimar dentro de las inequidades de género entorno a la notificación de infección por VIH/SIDA en mujeres. 


\section{Conclusiones}

- En Chile los primeros casos de SIDA se notificaron en 1984; desde esa fecha hasta el año 2012, las notificaciones alcanzan a 29.092 casos de infección por VIH o SIDA. De ellas 28.963 cuentan con etapa diagnóstica.

- Desde 1984 hasta el 2010, tanto la tasa de casos notificados de SIDA como de VIH, han ido en aumento, mostrando un descenso en el 2006 para luego mostrar un aumento sostenido hasta el 2009 y luego volver a bajar el 2010. Sin embargo, el 2011 se presenta la mayor tasa de notificación que para SIDA fue de 6,0 por cien mil habs. y para etapa VIH de 9,6 por cien mil habs. En el 2012 la tasa se mantuvo relativamente estable.

- El principal grupo poblacional afectado fue de adultos entre 20 y 49 años, específicamente el de 20 a 39 años. Se destaca que el grupo de 15 a 19 años mostró una tasa ascendente en el último quinquenio y que los niños de 5 a 9 años en el período 2008-2012 doblaron la tasa del quinquenio anterior.

- El número de casos en hombres superó ampliamente al de mujeres, tanto en etapa VIH como en etapa SIDA; sin embargo, las mujeres a través de los quinquenios mostraron un sostenido aumento, que en etapa SIDA es paulatino, mientras que en etapa VIH, este aumento es marcado.

- Las regiones que concentran las mayores tasas de infección por VIH/SIDA en los tres últimos quinquenios, son Arica y Parinacota, Tarapacá, Antofagasta, Valparaíso y la RM.

- Las tasas de etapa VIH en los dos últimos quinquenios, en todas las regiones, fueron mayores que las mostradas en etapa SIDA.

- La proporción de personas con educación media y superior fue más alto que la observada en la población general (Censo 2002). En general, los hombres tuvieron mayor nivel educacional que las mujeres.

- En Chile, la principal vía de transmisión es la sexual, representando 99\%, en el quinquenio 2008-2012. La vía más declarada es las prácticas de sexo entre hombres concentrando $61 \%$ de los casos en este mismo quinquenio. Por su parte, la vía heterosexual se ha mantenido constante.

- Del total de casos de infección por VIH/SIDA notificados en Chile entre 1988 y 2012, 56\% se notificó en etapa VIH mientras que $44 \%$ fue notificado ya en etapa SIDA, mostrándose una tendencia a la disminución de esta última en la primera notificación de los casos, situación que se espera profundizar, promoviendo el acceso al diagnóstico en etapas más precoces. El diagnóstico tardío es menor en mujeres probablemente por mayor acceso al test de detección (Programa de la
Mujer, control de embarazo, control de salud sexual, entre otros).

- El $98 \%$ de las personas notificadas en el último quinquenio es de nacionalidad chilena, el $2 \%$ restante se distribuye entre personas peruanas, colombianas y argentinas, mayoritariamente. Ellas han sido notificadas principalmente en las regiones de Tarapacá y Arica y Parinacota; sin embargo, las altas tasas de infección observadas en estas regiones no responden a la infección notificada en personas extranjeras.

- Las conductas sexuales inseguras fueron de alta prevalencia, y no presentan diferencias entre personas que declaran haber adquirido el VIH en relaciones heterosexuales, homosexuales o bisexuales. Ello implicaría la necesidad de profundizar las estrategias de prevención secundaria, lo que debiera tener un impacto individual y de salud pública.

- Hasta el 2011, fallecieron 7.842 personas a causa del SIDA. El 87\% de ellos corresponden a hombres. La tasa más alta de mortalidad se registra en el grupo de edad de 30 a 49 años. La Región de Arica y Parinacota mostró la tasa más elevada del país, siendo coincidente con las mayores tasas de notificación de infección por VIH/SIDA.

\section{Comentarios}

En Chile el VIH/SIDA se caracteriza por ser mayoritariamente de transmisión sexual, concentrada en hombres adultos jóvenes y fundamentalmente con prácticas homo/ bisexuales. Este perfil evidencia la mayor vulnerabilidad de estos grupos que además, presentan dificultades de acceso a las estrategias de prevención y a los servicios de salud disponibles.

Existe una tendencia a la disminución de los casos en etapa SIDA y una estabilización de la mortalidad, existiendo un incremento sostenido de nuevas infecciones dado por la incorporación del tratamiento anti-retroviral.

Profundizar en el conocimiento de las características de la epidemia y sus determinantes sociales permite enfocar de mejor manera las estrategias de prevención, evaluación e intervención socio-sanitarias, orientándolas hacia las diferentes poblaciones y comunidades en las cuales efectivamente reside la epidemia, o a aquellas que pueden derivar mayor beneficio logrando un impacto social en grupos vulnerables; además de utilizar adecuadamente los recursos asistenciales.

La condición social del hombre es inherente a su condición biológica y a los factores de riesgo que estos pueden transitar en su vida, por tanto, es necesario que los sistemas de vigilancia de infecciones de transmisión sexual consideren la integración de estos factores para sus respectivos análisis descriptivos. 
Los registros de notificación utilizado tienen falencias en la calidad de los datos, especialmente en lo de caracterización sociodemográfica por lo que se hace necesario reforzar en los médicos clínicos la importancia de llenar todas las variables consideradas en esta vigilancia, para conocer de mejor forma el comportamiento de la infección por VIH y con ello elaborar respuestas con pertinencia socio cultural.

Agradecimientos: Agradecemos a todas las personas que son parte de la red epidemiológica de vigilancia de infección por VIH/SIDA y de los Programas de Infección por VIH/SIDA e ITS que construyen y fortalecen esta vigilancia, así como aquellas que han participado en la revisión de este documento.

\section{Informe elaborado por:}

Karen Cáceres Burton

Depto de Epidemiología

División de Planificación Sanitaria

Pía Álvarez Iturriaga

Depto. Epidemiología

División de Planificación Sanitaria

\section{Con colaboración de:}

Programa Nacional de Prevención y Control del VIH/SIDA e ITS.

División de Prevención y Control de Enfermedades. Ministerio de Salud de Chile, Diciembre 2013.

\section{Anexos}

\section{Anexo 1. Tasa de notificación de SIDA y VIH según sexo. Chile 1984-2012*}

\begin{tabular}{|c|c|c|c|c|c|c|}
\hline & \multicolumn{5}{|c|}{ SIDA } \\
\hline Año & \multicolumn{2}{|c|}{ Hombres } & \multicolumn{2}{|c|}{ Mujeres } & \multicolumn{2}{c|}{ Total } \\
\hline & N $^{\circ}$ & Tasa & N $^{\circ}$ & Tasa & $\mathbf{N}^{\circ}$ & Tasa \\
\hline 1984 & 6 & 0,1 & 0 & 0,0 & 6 & 0,1 \\
\hline 1985 & 9 & 0,2 & 1 & 0,0 & 10 & 0,1 \\
\hline 1986 & 19 & 0,3 & 1 & 0,0 & 20 & 0,2 \\
\hline 1987 & 50 & 0,8 & 1 & 0,0 & 51 & 0,4 \\
\hline 1988 & 73 & 1,2 & 15 & 0,2 & 88 & 0,7 \\
\hline 1989 & 128 & 2,0 & 11 & 0,2 & 139 & 1,1 \\
\hline 1990 & 238 & 3,7 & 13 & 0,2 & 251 & 1,9 \\
\hline 1991 & 310 & 4,7 & 36 & 0,5 & 346 & 2,6 \\
\hline 1992 & 328 & 4,9 & 35 & 0,5 & 363 & 2,7 \\
\hline 1993 & 326 & 4,7 & 33 & 0,5 & 359 & 2,6 \\
\hline 1994 & 366 & 5,2 & 45 & 0,6 & 411 & 2,9 \\
\hline 1995 & 370 & 5,2 & 40 & 0,5 & 410 & 2,8 \\
\hline 1996 & 404 & 5,6 & 68 & 0,9 & 472 & 3,2 \\
\hline 1997 & 412 & 5,6 & 46 & 0,6 & 458 & 3,1 \\
\hline 1998 & 418 & 5,6 & 59 & 0,8 & 477 & 3,2 \\
\hline 1999 & 447 & 5,9 & 80 & 1,0 & 527 & 3,5 \\
\hline 2000 & 438 & 5,7 & 68 & 0,9 & 506 & 3,3 \\
\hline 2001 & 466 & 6,0 & 60 & 0,8 & 526 & 3,4 \\
\hline 2002 & 466 & 6,0 & 58 & 0,7 & 524 & 3,3 \\
\hline 2003 & 473 & 6,0 & 65 & 0,8 & 538 & 3,4 \\
\hline 2004 & 458 & 5,7 & 59 & 0,7 & 517 & 3,2 \\
\hline 2005 & 405 & 5,0 & 84 & 1,0 & 489 & 3,0 \\
\hline 2006 & 360 & 4,4 & 56 & 0,7 & 416 & 2,5 \\
\hline 2007 & 500 & 6,1 & 102 & 1,2 & 602 & 3,6 \\
\hline 2008 & 581 & 7,0 & 119 & 1,4 & 700 & 4,2 \\
\hline 2009 & 757 & 9,0 & 111 & 1,3 & 868 & 5,1 \\
\hline 2010 & 595 & 7,0 & 106 & 1,2 & 701 & 4,1 \\
\hline $2011^{*}$ & 875 & 10,2 & 153 & 1,8 & 1028 & 6,0 \\
\hline $2012^{*}$ & 795 & 9,2 & 137 & 1,6 & 932 & 5,4 \\
\hline Total & 11.073 & & 1.662 & & 11.803 & \\
\hline & & & & \\
\hline
\end{tabular}

\begin{tabular}{|c|c|c|c|c|c|}
\hline \multicolumn{7}{|c|}{ VIH } \\
\hline \multicolumn{2}{|c|}{ Hombres } & \multicolumn{2}{c|}{ Mujeres } & \multicolumn{2}{c|}{ Total } \\
\hline $\mathbf{N}^{\circ}$ & Tasa & $\mathbf{N}^{\circ}$ & Tasa & $\mathbf{N}^{\mathbf{0}}$ & Tasa \\
\hline 0 & 0,0 & 0 & 0,0 & 0 & 0,0 \\
\hline 1 & 0,0 & 0 & 0,0 & 1 & 0,0 \\
\hline 6 & 0,1 & 0 & 0,0 & 6 & 0,0 \\
\hline 22 & 0,4 & 3 & 0,0 & 25 & 0,2 \\
\hline 31 & 0,5 & 9 & 0,1 & 40 & 0,3 \\
\hline 64 & 1,0 & 7 & 0,1 & 71 & 0,5 \\
\hline 95 & 1,5 & 14 & 0,2 & 109 & 0,8 \\
\hline 157 & 2,4 & 23 & 0,3 & 180 & 1,3 \\
\hline 166 & 2,5 & 26 & 0,4 & 192 & 1,4 \\
\hline 210 & 3,1 & 31 & 0,4 & 241 & 1,7 \\
\hline 207 & 3,0 & 41 & 0,6 & 248 & 1,8 \\
\hline 261 & 3,7 & 43 & 0,6 & 304 & 2,1 \\
\hline 347 & 4,8 & 87 & 1,2 & 434 & 3,0 \\
\hline 392 & 5,4 & 92 & 1,2 & 484 & 3,3 \\
\hline 429 & 5,8 & 99 & 1,3 & 528 & 3,5 \\
\hline 510 & 6,8 & 117 & 1,5 & 627 & 4,1 \\
\hline 562 & 7,4 & 135 & 1,7 & 697 & 4,5 \\
\hline 557 & 7,2 & 141 & 1,8 & 698 & 4,5 \\
\hline 713 & 9,1 & 171 & 2,2 & 884 & 5,6 \\
\hline 765 & 9,7 & 175 & 2,2 & 940 & 5,9 \\
\hline 706 & 8,9 & 174 & 2,1 & 880 & 5,5 \\
\hline 702 & 8,7 & 169 & 2,1 & 871 & 5,4 \\
\hline 560 & 6,9 & 207 & 2,5 & 767 & 4,7 \\
\hline 547 & 6,7 & 164 & 2,0 & 711 & 4,3 \\
\hline 668 & 8,1 & 185 & 2,2 & 853 & 5,1 \\
\hline 1.010 & 12,1 & 227 & 2,7 & 1237 & 7,3 \\
\hline 851 & 10,1 & 192 & 2,2 & 1043 & 6,1 \\
\hline 1.394 & 16,3 & 260 & 3,0 & 1654 & 9,6 \\
\hline 1.240 & 14,4 & 263 & 3,0 & 1503 & 8,6 \\
\hline 13.173 & & 3.055 & & 16.228 & \\
\hline & & & & \\
\hline
\end{tabular}

\begin{tabular}{|c|c|c|c|c|c|}
\hline \multicolumn{7}{|c|}{ VIH/SIDA } \\
\hline \multicolumn{2}{|c|}{ Hombres } & \multicolumn{2}{|c|}{ Mujeres } & \multicolumn{2}{c|}{ Total } \\
\hline $\mathbf{N}^{\mathbf{0}}$ & Tasa & $\mathbf{N}^{\mathbf{0}}$ & Tasa & $\mathbf{N}^{\mathbf{}}$ & Tasa \\
\hline 6 & 0,0 & 0 & 0,0 & 6 & 0,1 \\
\hline 10 & 0,2 & 1 & 0,0 & 11 & 0,1 \\
\hline 25 & 0,4 & 1 & 0,0 & 26 & 0,2 \\
\hline 72 & 1,2 & 4 & 0,1 & 76 & 0,6 \\
\hline 104 & 1,7 & 24 & 0,4 & 128 & 1,0 \\
\hline 192 & 3,0 & 18 & 0,3 & 210 & 1,6 \\
\hline 333 & 5,1 & 27 & 0,4 & 360 & 2,7 \\
\hline 467 & 7,0 & 59 & 0,9 & 526 & 3,9 \\
\hline 494 & 7,3 & 61 & 0,9 & 555 & 4,1 \\
\hline 536 & 7,8 & 64 & 0,9 & 600 & 4,3 \\
\hline 573 & 8,2 & 86 & 1,2 & 659 & 4,7 \\
\hline 631 & 8,9 & 83 & 1,1 & 714 & 5,0 \\
\hline 751 & 10,4 & 155 & 2,1 & 906 & 6,2 \\
\hline 804 & 11,0 & 138 & 1,8 & 942 & 6,4 \\
\hline 847 & 11,4 & 158 & 2,1 & 1005 & 6,7 \\
\hline 957 & 12,7 & 197 & 2,6 & 1154 & 7,6 \\
\hline 1.000 & 13,1 & 203 & 2,6 & 1203 & 7,8 \\
\hline 1.023 & 13,3 & 201 & 2,6 & 1224 & 7,9 \\
\hline 1.179 & 15,1 & 229 & 2,9 & 1408 & 8,9 \\
\hline 1.238 & 15,7 & 240 & 3,0 & 1478 & 9,3 \\
\hline 1.164 & 14,6 & 233 & 2,9 & 1397 & 8,7 \\
\hline 1.107 & 13,7 & 253 & 3,1 & 1360 & 8,4 \\
\hline 920 & 11,3 & 263 & 3,2 & 1183 & 7,2 \\
\hline 1.047 & 12,7 & 266 & 3,2 & 1313 & 7,9 \\
\hline 1.249 & 15,1 & 304 & 3,6 & 1553 & 9,3 \\
\hline 1.767 & 21,1 & 338 & 4,0 & 2105 & 12,4 \\
\hline 1.446 & 17,1 & 298 & 3,5 & 1744 & 10,2 \\
\hline 2.269 & 26,6 & 413 & 4,7 & 2682 & 15,5 \\
\hline 2.035 & 23,6 & 400 & 4,6 & 2435 & 14,0 \\
\hline 24.246 & & 4.717 & & 28.963 & \\
\hline & & & & & \\
\hline
\end{tabular}

Fuente: Formulario notificación de VIH/SIDA, Depto Epidemiología, MINSAL.

*Tasa por cien mil habs. 
Anexo 2. Tasa de notificación de VIH y SIDA según grupos de edad, quinquenio y clasificación. Chile 1987-2012*

\begin{tabular}{|c|c|c|c|c|c|c|c|c|c|c|}
\hline \multirow[t]{2}{*}{ Grupo Edad } & \multicolumn{2}{|c|}{ 1988-1992 } & \multicolumn{2}{|c|}{ 1993-1997 } & \multicolumn{2}{|c|}{$1998-2002$} & \multicolumn{2}{|c|}{ 2003-2007 } & \multicolumn{2}{|c|}{ 2008-2012 } \\
\hline & $\mathrm{N}^{\circ}$ & Tasa* & $\mathrm{N}^{\circ}$ & Tasa* & $\mathrm{N}^{\circ}$ & Tasa* & $\mathrm{N}^{\circ}$ & Tasa* & $\mathrm{N}^{\circ}$ & Tasa* \\
\hline \multicolumn{11}{|c|}{ SIDA } \\
\hline $0-4$ & 17 & 1,2 & 23 & 1,5 & 37 & 2,8 & 32 & 2,6 & 19 & 1,5 \\
\hline $5-9$ & 2 & 0,2 & 2 & 0,1 & 2 & 0,1 & 4 & 0,3 & 8 & 0,6 \\
\hline $10-14$ & 3 & 0,3 & 2 & 0,2 & 2 & 0,1 & 4 & 0,3 & 5 & 0,4 \\
\hline $15-19$ & 36 & 2,9 & 32 & 2,7 & 37 & 2,8 & 20 & 1,4 & 48 & 3,2 \\
\hline $20-29$ & 433 & 17,3 & 676 & 27,2 & 596 & 24,7 & 492 & 19,7 & 882 & 31,7 \\
\hline $30-39$ & 379 & 19,0 & 785 & 33,0 & 1.005 & 40,0 & 898 & 36,2 & 1376 & 57,2 \\
\hline $40-49$ & 203 & 14,8 & 373 & 23,1 & 531 & 26,9 & 675 & 28,7 & 1109 & 44,7 \\
\hline $50-59$ & 76 & 8,0 & 159 & 14,3 & 252 & 19,0 & 304 & 19,5 & 547 & 28,7 \\
\hline $60-69$ & 33 & 4,9 & 48 & 6,2 & 80 & 9,4 & 105 & 10,4 & 197 & 16,3 \\
\hline 70 y más & 5 & 1,0 & 10 & 1,7 & 18 & 2,5 & 28 & 3,3 & 38 & 3,8 \\
\hline Total & 1.187 & 9,0 & 2.110 & 14,7 & 2.560 & 16,6 & 2.562 & 15,7 & 4.229 & 24,7 \\
\hline \multicolumn{11}{|c|}{ VIH } \\
\hline $0-4$ & 2 & 0,1 & 24 & 1,6 & 28 & 2,1 & 36 & 2,9 & 26 & 2,1 \\
\hline $5-9$ & 0 & 0,0 & 3 & 0,2 & 9 & 0,6 & 9 & 0,7 & 15 & 1,2 \\
\hline $10-14$ & 0 & 0,0 & 3 & 0,2 & 6 & 0,4 & 7 & 0,5 & 12 & 0,9 \\
\hline $15-19$ & 34 & 2,8 & 49 & 4,2 & 154 & 11,6 & 205 & 14,0 & 349 & 23,4 \\
\hline $20-29$ & 270 & 10,8 & 728 & 29,3 & 1253 & 51,9 & 1554 & 62,3 & 2753 & 98,9 \\
\hline $30-39$ & 183 & 9,2 & 598 & 25,1 & 1271 & 50,6 & 1373 & 55,4 & 1791 & 74,4 \\
\hline $40-49$ & 71 & 5,2 & 190 & 11,8 & 480 & 24,3 & 672 & 28,6 & 915 & 36,9 \\
\hline $50-59$ & 19 & 2,0 & 85 & 7,6 & 183 & 13,8 & 233 & 14,9 & 326 & 17,1 \\
\hline $60-69$ & 9 & 1,3 & 25 & 3,2 & 39 & 4,6 & 63 & 6,2 & 87 & 7,2 \\
\hline 70 y más & 4 & 0,8 & 6 & 1,0 & 11 & 1,5 & 17 & 2,0 & 16 & 1,6 \\
\hline Total & 592 & 4,5 & 1.711 & 11,9 & 3.434 & 22,3 & 4.169 & 25,6 & 6.290 & 36,8 \\
\hline
\end{tabular}

Fuente: Formulario caso VIH/SIDA, Depto Epidemiología. MINSAL.

*Tasa por cien mil habs.

Anexo 3. Casos de VIH y SIDA según grupo de edad, quinquenio y sexo. Chile 1988-2012*

\begin{tabular}{|c|c|c|c|c|c|c|c|c|c|c|}
\hline \multirow[t]{2}{*}{ Grupo edad } & \multicolumn{2}{|c|}{ 1988-1992 } & \multicolumn{2}{|c|}{ 1993-1997 } & \multicolumn{2}{|c|}{ 1998-2002 } & \multicolumn{2}{|c|}{$2003-2007$} & \multicolumn{2}{|c|}{$2008-2012$} \\
\hline & $\mathrm{N}^{\circ}$ & Tasa* & $\mathrm{N}^{\circ}$ & Tasa* & $\mathrm{N}^{\circ}$ & Tasa* & $\mathrm{N}^{\circ}$ & Tasa* & $\mathrm{N}^{\circ}$ & Tasa* \\
\hline \multicolumn{11}{|c|}{ Mujeres } \\
\hline $0-4$ & 9 & 1,3 & 29 & 4,0 & 28 & 4,3 & 31 & 5,1 & 28 & 4,6 \\
\hline $5-9$ & 1 & 0,2 & 2 & 0,3 & 6 & 0,8 & 8 & 1,2 & 13 & 2,1 \\
\hline $10-14$ & 0 & - & 3 & 0,5 & 5 & 0,7 & 7 & 1,0 & 12 & 1,8 \\
\hline 15-19 & 14 & 2,3 & 19 & 3,3 & 57 & 8,8 & 70 & 9,7 & 88 & 12,0 \\
\hline $20-29$ & 72 & 5,8 & 212 & 17,2 & 330 & 27,6 & 414 & 33,6 & 510 & 37,1 \\
\hline $30-39$ & 52 & 5,2 & 155 & 13,0 & 312 & 24,8 & 391 & 31,6 & 518 & 43,2 \\
\hline $40-49$ & 21 & 3,0 & 61 & 7,5 & 155 & 15,6 & 237 & 20,0 & 357 & 28,6 \\
\hline $50-59$ & 12 & 2,4 & 37 & 6,4 & 65 & 9,5 & 84 & 10,5 & 164 & 16,8 \\
\hline $60-69$ & 7 & 1,9 & 7 & 1,7 & 24 & 5,2 & 26 & 4,8 & 52 & 8,1 \\
\hline 70 y más & 1 & 0,3 & 1 & 0,3 & 7 & 1,6 & 9 & 1,8 & 11 & 1,9 \\
\hline Total & 189 & 2,8 & 526 & 7,2 & 989 & 12,7 & 1.277 & 15,5 & 1.753 & 20,3 \\
\hline \multicolumn{11}{|c|}{ Hombres } \\
\hline $0-4$ & 10 & 1,4 & 18 & 2,5 & 37 & 5,7 & 39 & 6,4 & 17 & 2,8 \\
\hline $5-9$ & 1 & 0,2 & 3 & 0,4 & 5 & 0,7 & 5 & 0,8 & 10 & 1,6 \\
\hline $10-14$ & 3 & 0,5 & 2 & 0,3 & 3 & 0,4 & 4 & 0,5 & 5 & 0,8 \\
\hline $15-19$ & 56 & 9,2 & 62 & 10,7 & 134 & 20,6 & 157 & 21,8 & 309 & 42,2 \\
\hline $20-29$ & 631 & 50,7 & 1192 & 96,7 & 1521 & 127,1 & 1671 & 135,6 & 3125 & 227,5 \\
\hline $30-39$ & 510 & 51,2 & 1231 & 103,4 & 1968 & 156,6 & 1914 & 154,5 & 2649 & 220,8 \\
\hline $40-49$ & 253 & 36,1 & 503 & 61,5 & 859 & 86,2 & 1136 & 95,9 & 1667 & 133,4 \\
\hline $50-59$ & 83 & 16,6 & 207 & 35,8 & 371 & 54,3 & 462 & 57,8 & 709 & 72,8 \\
\hline $60-69$ & 35 & 9,5 & 66 & 15,7 & 95 & 20,6 & 143 & 26,6 & 232 & 36,2 \\
\hline 70 y más & 8 & 2,6 & 15 & 4,2 & 24 & 5,6 & 36 & 7,0 & 43 & 7,3 \\
\hline Total & 1.590 & 23,8 & 3.299 & 45,4 & 5.017 & 64,5 & 5.567 & 67,8 & 8.766 & 101,5 \\
\hline
\end{tabular}

Fuente: Formulario caso VIH/SIDA, Depto Epidemiología. MINSAL.

*Información preliminar. 
Anexo 4. Tasa de notificación de VIH y SIDA según región y quinquenios. Chile 1987-2012*

\begin{tabular}{|c|c|c|c|c|c|c|c|c|c|c|}
\hline \multirow[t]{2}{*}{ Región } & \multicolumn{2}{|c|}{ 1988-1992 } & \multicolumn{2}{|c|}{ 1993-1997 } & \multicolumn{2}{|c|}{ 1998-2002 } & \multicolumn{2}{|c|}{ 2003-2007 } & \multicolumn{2}{|c|}{$2008-2012$} \\
\hline & $\mathrm{N}^{\circ}$ & Tasa* & $\mathrm{N}^{\circ}$ & Tasa* & $\mathrm{N}^{\circ}$ & Tasa* & $\mathrm{N}^{\circ}$ & Tasa* & $\mathrm{N}^{\circ}$ & Tasa* \\
\hline \multicolumn{11}{|c|}{ SIDA } \\
\hline Arica y Parinacota & 8 & 4,6 & 36 & 20,0 & 67 & 35,1 & 80 & 43,3 & 130 & 70,3 \\
\hline Tarapacá & 11 & 6,7 & 11 & 5,4 & 81 & 29,0 & 66 & 21,0 & 121 & 38,5 \\
\hline Antofagasta & 23 & 5,7 & 54 & 11,8 & 80 & 14,8 & 82 & 14,3 & 126 & 21,9 \\
\hline Atacama & 1 & 0,4 & 9 & 3,7 & 12 & 4,4 & 38 & 13,5 & 79 & 28,2 \\
\hline Coquimbo & 16 & 3,2 & 27 & 4,8 & 71 & 10,6 & 82 & 11,4 & 168 & 23,4 \\
\hline Valparaíso & 201 & 14,7 & 269 & 18,5 & 326 & 19,6 & 316 & 18,0 & 558 & 31,7 \\
\hline Metropolitana & 843 & 16,2 & 1.453 & 25,5 & 1.445 & 22,1 & 1.301 & 18,9 & 1.929 & 28,0 \\
\hline O’Higgins & 6 & 0,9 & 31 & 4,1 & 40 & 4,8 & 80 & 9,1 & 154 & 17,4 \\
\hline Maule & 15 & 1,8 & 45 & 5,0 & 97 & 10,0 & 87 & 8,6 & 144 & 14,3 \\
\hline Bío-Bío & 38 & 2,2 & 92 & 5,0 & 195 & 9,9 & 234 & 11,5 & 369 & 18,1 \\
\hline Araucanía & 5 & 0,6 & 22 & 2,6 & 71 & 7,6 & 73 & 7,5 & 162 & 16,7 \\
\hline Los Ríos & 7 & 2,1 & 24 & 6,8 & 22 & 5,9 & 35 & 9,2 & 77 & 20,3 \\
\hline Los Lagos & 11 & 1,8 & 25 & 3,7 & 38 & 4,8 & 76 & 9,1 & 195 & 23,3 \\
\hline Aisén & 0 & 0,0 & 3 & 3,4 & 8 & 8,1 & 3 & 2,9 & 3 & 2,9 \\
\hline Magallanes & 2 & 1,4 & 9 & 6,2 & 7 & 4,5 & 9 & 5,7 & 14 & 8,8 \\
\hline Total & 1.187 & 9,0 & 2.110 & 14,7 & 2.560 & 15,7 & 2.562 & 15,0 & 4.229 & 24,7 \\
\hline \multicolumn{11}{|c|}{ VIH } \\
\hline Arica y Parinacota & 10 & 5,8 & 37 & 20,6 & 82 & 43,0 & 113 & 61,1 & 179 & 96,8 \\
\hline Tarapacá & 5 & 3,1 & 11 & 5,4 & 83 & 29,7 & 115 & 36,6 & 155 & 49,3 \\
\hline Antofagasta & 8 & 2,0 & 32 & 7,0 & 143 & 26,4 & 189 & 32,9 & 254 & 44,2 \\
\hline Atacama & 2 & 0,9 & 5 & 2,0 & 28 & 10,4 & 59 & 21,0 & 88 & 31,4 \\
\hline Coquimbo & 9 & 1,8 & 36 & 6,4 & 121 & 18,1 & 143 & 19,9 & 213 & 29,6 \\
\hline Valparaíso & 87 & 6,4 & 256 & 17,6 & 462 & 27,8 & 432 & 24,6 & 540 & 30,7 \\
\hline Metropolitana & 439 & 8,5 & 1.171 & 20,5 & 1.977 & 30,2 & 2.135 & 31,0 & 3.388 & 49,2 \\
\hline O'Higgins & 10 & 1,5 & 31 & 4,1 & 70 & 8,3 & 144 & 16,3 & 140 & 15,8 \\
\hline Maule & 9 & 1,1 & 36 & 4,0 & 103 & 10,7 & 149 & 14,8 & 161 & 16,0 \\
\hline Bío-Bío & 6 & 0,4 & 50 & 2,7 & 148 & 7,5 & 314 & 15,4 & 490 & 24,1 \\
\hline Araucanía & & 0,0 & 12 & 1,4 & 80 & 8,6 & 85 & 8,8 & 165 & 17,0 \\
\hline Los Ríos & 2 & 0,6 & 8 & 2,3 & 17 & 4,6 & 76 & 20,0 & 111 & 29,2 \\
\hline Los Lagos & 4 & 0,7 & 14 & 2,0 & 102 & 13,0 & 177 & 21,2 & 331 & 39,6 \\
\hline Aisén & & 0,0 & 3 & 3,4 & 8 & 8,1 & 16 & 15,3 & 30 & 28,6 \\
\hline Magallanes & 1 & 0,7 & 9 & 6,2 & 10 & 6,4 & 22 & 13,9 & 45 & 28,4 \\
\hline Total & 592 & 4,5 & 1.711 & 11,9 & 3.434 & 21,1 & 4.169 & 24,4 & 6.290 & 36,8 \\
\hline \multicolumn{11}{|c|}{ VIH/SIDA } \\
\hline Arica y Parinacota & 18 & 10,5 & 73 & 40,6 & 149 & 77,0 & 193 & 101,1 & 309 & 167,1 \\
\hline Tarapacá & 16 & 9,8 & 22 & 10,9 & 164 & 67,0 & 181 & 64,9 & 276 & 87,7 \\
\hline Antofagasta & 31 & 7,6 & 86 & 18,7 & 223 & 44,1 & 271 & 50,1 & 380 & 66,1 \\
\hline Atacama & 3 & 1,3 & 14 & 5,7 & 40 & 15,4 & 97 & 35,9 & 167 & 59,5 \\
\hline Coquimbo & 25 & 5,0 & 63 & 11,3 & 192 & 31,2 & 225 & 33,7 & 381 & 53,0 \\
\hline Valparaíso & 288 & 21,1 & 525 & 36,1 & 788 & 50,4 & 748 & 45,0 & 1.098 & 62,4 \\
\hline Metropolitana & 1.282 & 24,7 & 2.624 & 46,0 & 3.422 & 55,5 & 3.436 & 52,5 & 5317 & 77,2 \\
\hline O’Higgins & 16 & 2,3 & 62 & 8,2 & 110 & 13,8 & 224 & 26,6 & 294 & 33,3 \\
\hline Maule & 24 & 2,9 & 81 & 9,1 & 200 & 21,6 & 236 & 24,4 & 305 & 30,3 \\
\hline Bío-Bío & 44 & 2,6 & 142 & 7,7 & 343 & 18,1 & 548 & 27,8 & 859 & 42,2 \\
\hline Araucanía & 5 & 0,6 & 34 & 4,0 & 151 & 17,0 & 158 & 17,0 & 327 & 33,7 \\
\hline Los Ríos & 9 & 2,8 & 32 & 9,1 & 39 & 10,8 & 111 & 29,8 & 188 & 49,5 \\
\hline Los Lagos & 15 & 2,5 & 39 & 5,7 & 140 & 19,1 & 253 & 32,3 & 526 & 62,9 \\
\hline Aisén & 0 & 0,0 & 6 & 6,9 & 16 & 17,1 & 19 & 19,1 & 33 & 31,5 \\
\hline Magallanes & 3 & 2,1 & 18 & 12,5 & 17 & 11,1 & 31 & 19,9 & 59 & 37,2 \\
\hline Total & 1.779 & 13,5 & 3.821 & 26,5 & 5.994 & 38,9 & 6731 & 41,4 & 10.519 & 61,5 \\
\hline
\end{tabular}

Fuente: Formulario caso VIH/SIDA, Depto Epidemiología. MINSAL.

*Tasa por cien mil habs. 
Anexo 5. Casos de VIH y SIDA según nivel de escolaridad, quinquenio y sexo. Chile 1988-2012*

\begin{tabular}{|c|c|c|c|c|c|c|c|c|c|c|}
\hline \multirow[t]{2}{*}{ Escolaridad } & \multicolumn{2}{|c|}{ 1988-1992 } & \multicolumn{2}{|c|}{ 1993-1997 } & \multicolumn{2}{|c|}{ 1998-2002 } & \multicolumn{2}{|c|}{ 2003-2007 } & \multicolumn{2}{|c|}{ 2008-2012 } \\
\hline & $\mathrm{N}^{\circ}$ & $\%$ & $\mathrm{~N}^{\circ}$ & $\%$ & $\mathrm{~N}^{\circ}$ & $\%$ & $\mathrm{~N}^{\circ}$ & $\%$ & $\mathrm{~N}^{\mathrm{O}}$ & $\%$ \\
\hline \multicolumn{11}{|c|}{ Mujeres } \\
\hline Pre-escolar & 0 & - & 0 & - & 0 & - & 1 & 0,1 & 8 & 0,5 \\
\hline Basica & 60 & 31,7 & 204 & 38,8 & 393 & 39,7 & 424 & 33,2 & 445 & 25,4 \\
\hline Media & 87 & 46,0 & 199 & 37,8 & 396 & 40,0 & 531 & 41,6 & 753 & 43,0 \\
\hline Superior & 17 & 9,0 & 48 & 9,1 & 92 & 9,3 & 126 & 9,9 & 159 & 9,1 \\
\hline Técnica & 0 & - & 0 & - & 0 & - & 12 & 0,9 & 137 & 7,8 \\
\hline Ninguna & 12 & 6,3 & 37 & 7,0 & 53 & 5,4 & 46 & 3,6 & 43 & 2,5 \\
\hline Desconocido & 13 & 6,9 & 38 & 7,2 & 55 & 5,6 & 137 & 10,7 & 208 & 11,9 \\
\hline Total & 189 & 100 & 526 & 100 & 989 & 100 & 1.277 & 100 & 1.753 & 100 \\
\hline \multicolumn{11}{|c|}{ Hombres } \\
\hline Pre-escolar & - & - & - & - & - & - & 1 & 0,0 & 7 & 0,1 \\
\hline Basica & 362 & 22,8 & 753 & 22,8 & 1.101 & 21,9 & 892 & 16,0 & 936 & 10,7 \\
\hline Media & 732 & 46,0 & 1.623 & 49,2 & 2.430 & 48,4 & 2.553 & 45,9 & 3.238 & 36,9 \\
\hline Superior & 339 & 21,3 & 670 & 20,3 & 1.088 & 21,7 & 1.400 & 25,1 & 2.288 & 26,1 \\
\hline Técnica & - & - & - & - & - & - & 76 & 1,4 & 1.148 & 13,1 \\
\hline Ninguna & 17 & 1,1 & 46 & 1,4 & 79 & 1,6 & 71 & 1,3 & 59 & 0,7 \\
\hline Desconocido & 140 & 8,8 & 207 & 6,3 & 319 & 6,4 & 574 & 10,3 & 1.090 & 12,4 \\
\hline Total & 1.590 & 100 & 3.299 & 100 & 5.017 & 100 & 5.567 & 100 & 8.766 & 100 \\
\hline
\end{tabular}

Fuente: Formulario caso VIH/SIDA, Depto Epidemiología. MINSAL. *Información preliminar.

Anexo 6. Casos de SIDA según vía de exposición, quinquenio y sexo. Chile 1988-2012*

\begin{tabular}{|c|c|c|c|c|c|c|c|c|c|c|}
\hline \multirow[t]{2}{*}{ Vía de exposición } & \multicolumn{2}{|c|}{ 1988-1992 } & \multicolumn{2}{|c|}{ 1993-1997 } & \multicolumn{2}{|c|}{$1998-2002$} & \multicolumn{2}{|c|}{ 2003-2007 } & \multicolumn{2}{|c|}{$2008-2012$} \\
\hline & $\mathrm{N}^{\circ}$ & $\%$ & $\mathrm{~N}^{\circ}$ & $\%$ & $\mathrm{~N}^{\circ}$ & $\%$ & $\mathrm{~N}^{\circ}$ & $\%$ & $\mathrm{~N}^{\circ}$ & $\%$ \\
\hline \multicolumn{11}{|l|}{ MUJERES } \\
\hline Heterosexual & 88 & 80,7 & 195 & 86,7 & 289 & 92,6 & 321 & 95,5 & 536 & 97,3 \\
\hline Vía sanguínea & 12 & 11,0 & 16 & 7,1 & 8 & 2,6 & 4 & 1 & 0 & - \\
\hline Vertical & 9 & 8,3 & 14 & 6,2 & 15 & 4,8 & 11 & 3 & 15 & 2,7 \\
\hline Total & 109 & 100 & 225 & 100 & 312 & 100 & 336 & 100 & 551 & 100 \\
\hline \multicolumn{11}{|c|}{ HOMBRES } \\
\hline Homosexual & 582 & 57,9 & 925 & 53,3 & 1014 & 49,1 & 895 & 46,3 & 1423 & 50,1 \\
\hline Bisexual & 231 & 23,0 & 318 & 18,3 & 385 & 18,6 & 286 & 14,8 & 362 & 12,7 \\
\hline Heterosexual & 122 & 12,1 & 390 & 22,5 & 603 & 29,2 & 720 & 37,2 & 1040 & 36,6 \\
\hline Vía sanguínea & 61 & 6,1 & 92 & 5,3 & 40 & 1,9 & 12 & 0,6 & 9 & 0,3 \\
\hline Vertical & 9 & 0,9 & 10 & 0,6 & 24 & 1,2 & 20 & 1,0 & 7 & 0,2 \\
\hline Total & 1.005 & 100 & 1.735 & 100 & 2.066 & 100 & 1.933 & 100 & 2.841 & 100 \\
\hline
\end{tabular}

Fuente: Formulario caso VIH/SIDA, Depto Epidemiología. MINSAL. *Información preliminar.

Anexo 7. Casos de VIH según vía de exposición, quinquenio y sexo. Chile 1988-2012*

\begin{tabular}{|c|c|c|c|c|c|c|c|c|c|c|}
\hline \multirow[t]{2}{*}{ Vía de exposición } & \multicolumn{2}{|c|}{ 1988-1992 } & \multicolumn{2}{|c|}{ 1993-1997 } & \multicolumn{2}{|c|}{ 1998-2002 } & \multicolumn{2}{|c|}{$2003-2007$} & \multicolumn{2}{|c|}{$2008-2012$} \\
\hline & $\mathrm{N}^{\circ}$ & $\%$ & $\mathrm{~N}^{\circ}$ & $\%$ & $\mathrm{~N}^{\circ}$ & $\%$ & $\mathrm{~N}^{\circ}$ & $\%$ & $\mathrm{~N}^{\circ}$ & $\%$ \\
\hline \multicolumn{11}{|c|}{ Mujeres } \\
\hline Heterosexual & 64 & 82,1 & 262 & 91,0 & 616 & 95,1 & 798 & 96,0 & 1034 & 98,1 \\
\hline Vía sanguínea & 13 & 16,7 & 11 & 3,8 & 12 & 1,9 & 6 & 0,7 & 3 & 0,3 \\
\hline Vertical & 1 & 1,3 & 15 & 5,2 & 20 & 3,1 & 27 & 3,2 & 17 & 1,6 \\
\hline Total & 78 & 100 & 288 & 100 & 648 & 100 & 831 & 100 & 1054 & 100 \\
\hline \multicolumn{11}{|c|}{ Hombres } \\
\hline Homosexual & 281 & 57,5 & 803 & 59,7 & 1642 & 61,6 & 1.864 & 60,4 & 3120 & 69,0 \\
\hline Bisexual & 97 & 19,8 & 207 & 15,4 & 369 & 13,8 & 403 & 13,1 & 481 & 10,6 \\
\hline Heterosexual & 80 & 16,4 & 248 & 18,5 & 590 & 22,1 & 795 & 25,7 & 902 & 19,9 \\
\hline Vía sanguínea & 30 & 6,1 & 77 & 5,7 & 47 & 1,8 & 12 & 0,4 & 8 & 0,2 \\
\hline Vertical & 1 & 0,2 & 9 & 0,7 & 18 & 0,7 & 14 & 0,5 & 13 & 0,3 \\
\hline Total & 489 & 100 & 1.344 & 100 & 2.666 & 100 & 3.088 & 100 & 4.524 & 100 \\
\hline
\end{tabular}

Fuente: Formulario caso VIH/SIDA, Depto Epidemiología. MINSAL. *Información preliminar. 
Anexo 8. Distribución porcentual por etapa diagnóstica en la primera notificación, según sexo y quinquenio. Chile 1987-2012*

\begin{tabular}{|c|c|c|c|c|c|c|c|c|c|c|}
\hline \multirow[t]{2}{*}{ Etapa diagnóstica } & \multicolumn{2}{|c|}{ 1988-1992 } & \multicolumn{2}{|c|}{ 1993-1997 } & \multicolumn{2}{|c|}{$1998-2002$} & \multicolumn{2}{|c|}{ 2003-2007 } & \multicolumn{2}{|c|}{ 2008-2012 } \\
\hline & $N^{\circ}$ & $\%$ & $\mathrm{~N}^{\circ}$ & $\%$ & $\mathrm{~N}^{\circ}$ & $\%$ & $\mathrm{~N}^{\circ}$ & $\%$ & $\mathrm{~N}^{\circ}$ & $\%$ \\
\hline \multicolumn{11}{|c|}{ Mujeres } \\
\hline $\mathrm{VIH}$ & 79 & 41,8 & 294 & 55,9 & 663 & 67,1 & 889 & 70,8 & 1.127 & 64,3 \\
\hline SIDA & 110 & 58,2 & 232 & 44,1 & 325 & 32,9 & 366 & 29,2 & 626 & 35,7 \\
\hline Total & 189 & 100 & 526 & 100 & 988 & 100 & 1.255 & 100 & 1.753 & 100 \\
\hline \multicolumn{11}{|c|}{ Hombres } \\
\hline $\mathrm{VIH}$ & 513 & 32,3 & 1.417 & 43,0 & 2.771 & 55,4 & 3.280 & 59,9 & 5.163 & 58,9 \\
\hline SIDA & 1.077 & 67,7 & 1.878 & 57,0 & 2.235 & 44,6 & 2.196 & 40,1 & 3.603 & 41,1 \\
\hline Total & 1.590 & 100 & 3.295 & 100 & 5.006 & 100 & 5.476 & 100 & 8.766 & 100 \\
\hline
\end{tabular}

Fuente: Formulario caso VIH/SIDA, Depto Epidemiología. MINSAL.

*Información preliminar.

Anexo 9. Mortalidad por SIDA según sexo. Chile 1990-2011

\begin{tabular}{|c|c|c|c|c|c|c|c|}
\hline \multirow[t]{2}{*}{ Año } & \multicolumn{2}{|c|}{ Ambos sexos } & \multicolumn{2}{|c|}{ Hombres } & \multicolumn{2}{|c|}{ Mujeres } & \multirow{2}{*}{$\begin{array}{l}\text { Razón } \\
\mathrm{H}: \mathrm{M}\end{array}$} \\
\hline & $\mathbf{N}^{\circ}$ Def. & Tasa* & $\mathbf{N}^{\circ}$ Def. & Tasa* & $\mathrm{N}^{\circ}$ Def. & Tasa* & \\
\hline 1990 & 72 & 0,5 & 66 & 1,0 & 6 & 0,1 & 11 \\
\hline 1991 & 77 & 0,6 & 75 & 1,1 & 2 & 0,0 & 37,5 \\
\hline 1992 & 114 & 0,8 & 101 & 1,5 & 13 & 0,2 & 7,8 \\
\hline 1993 & 174 & 1,3 & 163 & 2,4 & 11 & 0,2 & 14,8 \\
\hline 1994 & 253 & 1,8 & 227 & 3,2 & 26 & 0,4 & 8,7 \\
\hline 1995 & 302 & 2,1 & 278 & 3,9 & 24 & 0,3 & 11,6 \\
\hline 1996 & 362 & 2,5 & 317 & 4,4 & 45 & 0,6 & 7,0 \\
\hline 1997 & 410 & 2,8 & 360 & 5,0 & 50 & 0,7 & 7,2 \\
\hline 1998 & 383 & 2,6 & 343 & 4,6 & 40 & 0,5 & 8,6 \\
\hline 1999 & 474 & 3,1 & 424 & 5,6 & 50 & 0,7 & 8,5 \\
\hline 2000 & 458 & 3,0 & 402 & 5,3 & 56 & 0,7 & 7,2 \\
\hline 2001 & 552 & 3,5 & 479 & 6,2 & 73 & 0,9 & 6,6 \\
\hline 2002 & 440 & 2,8 & 380 & 4,9 & 60 & 0,8 & 6,3 \\
\hline 2003 & 423 & 2,7 & 357 & 4,5 & 66 & 0,8 & 5,4 \\
\hline 2004 & 399 & 2,5 & 356 & 4,5 & 43 & 0,5 & 8,3 \\
\hline 2005 & 395 & 2,4 & 333 & 4,1 & 62 & 0,8 & 5,4 \\
\hline 2006 & 422 & 2,6 & 357 & 4,4 & 65 & 0,8 & 5,5 \\
\hline 2007 & 398 & 2,4 & 347 & 4,2 & 51 & 0,6 & 6,8 \\
\hline 2008 & 392 & 2,3 & 328 & 4,0 & 64 & 0,8 & 5,1 \\
\hline 2009 & 435 & 2,6 & 365 & 4,4 & 70 & 0,8 & 5,2 \\
\hline 2010 & 435 & 2,5 & 370 & 4,4 & 65 & 0,8 & 5,7 \\
\hline 2011 & 472 & 2,7 & 386 & 4,5 & 86 & 1,1 & 4,5 \\
\hline TOTAL & 7.370 & & 6.814 & & 1.028 & & \\
\hline
\end{tabular}

Fuente: DEIS, MINSAL.

*Tasa por cien mil habitantes 
Anexo 10. Mortalidad por SIDA según grupos de edad y sexo. Chile 2007-2011

\begin{tabular}{|c|c|c|c|c|c|c|c|c|c|c|}
\hline \multirow[t]{2}{*}{ Grupo edad } & \multicolumn{2}{|c|}{2007} & \multicolumn{2}{|c|}{2008} & \multicolumn{2}{|c|}{2009} & \multicolumn{2}{|c|}{2010} & \multicolumn{2}{|c|}{2011} \\
\hline & $\mathrm{N}^{\circ}$ & Tasa* & $\mathrm{N}^{\circ}$ & Tasa* & $\mathbf{N}^{\circ}$ & Tasa* & $\mathrm{N}^{\circ}$ & Tasa* & $\mathrm{N}^{\circ}$ & Tasa* \\
\hline \multicolumn{11}{|c|}{ Mujeres } \\
\hline $0-9$ & 0 & - & 26 & 0,2 & 32 & - & 43 & 0,2 & 42 & 0,1 \\
\hline $10-14$ & 0 & - & 1 & 0,1 & 0 & - & 0 & - & 0 & - \\
\hline $15-19$ & 1 & 0,1 & 0 & - & 0 & - & 0 & - & 0 & - \\
\hline $20-29$ & 5 & 0,4 & 6 & 0,5 & 10 & 0,7 & 6 & 0,4 & 11 & 0,8 \\
\hline 30-39 & 14 & 1,1 & 26 & 2,1 & 25 & 2,1 & 18 & 1,5 & 24 & 2,0 \\
\hline $40-49$ & 12 & 1,0 & 16 & 1,3 & 19 & 1,5 & 21 & 1,7 & 26 & 2,1 \\
\hline $50-59$ & 11 & 1,3 & 7 & 0,8 & 10 & 1,1 & 11 & 1,1 & 9 & 0,9 \\
\hline $60-69$ & 7 & 1,2 & 5 & 0,8 & 5 & 0,8 & 5 & 0,8 & 12 & 1,8 \\
\hline 70 y más & 1 & 0,2 & 1 & 0,2 & 1 & 0,2 & 1 & 0,2 & 3 & 0,5 \\
\hline Total & 51 & 0,7 & 64 & 0,8 & 70 & 0,9 & 65 & 0,8 & 86 & 1,1 \\
\hline \multicolumn{11}{|c|}{ Hombres } \\
\hline $0-9$ & 10 & 0,2 & 17 & 0,2 & 40 & 0,2 & 44 & 0,3 & 36 & 0,2 \\
\hline $10-14$ & 0 & - & 0 & - & 0 & - & 0 & - & 0 & - \\
\hline $15-19$ & 0 & - & 1 & 0,1 & 4 & 0,5 & 0 & - & 0 & - \\
\hline 20-29 & 48 & 3,6 & 34 & 2,5 & 51 & 3,7 & 51 & 3,6 & 38 & 2,7 \\
\hline $30-39$ & 102 & 8,3 & 117 & 9,6 & 91 & 7,5 & 97 & 8,0 & 118 & 9,7 \\
\hline $40-49$ & 110 & 9,2 & 97 & 8,0 & 122 & 10,0 & 113 & 9,2 & 119 & 9,7 \\
\hline $50-59$ & 53 & 6,4 & 50 & 5,8 & 70 & 7,8 & 68 & 7,3 & 68 & 7,0 \\
\hline $60-69$ & 26 & 5,1 & 23 & 4,3 & 20 & 3,6 & 27 & 4,7 & 31 & 5,2 \\
\hline 70 y más & 6 & 1,6 & 4 & 1,0 & 5 & 1,3 & 10 & 2,4 & 10 & 2,3 \\
\hline Total & 347 & 4,6 & 328 & 4,3 & 365 & 4,7 & 370 & 4,7 & 386 & 4,9 \\
\hline
\end{tabular}

Fuente:Base defunciones, DEIS, MINSAL.

* Tasa por cien mil habitantes

Anexo 11. Mortalidad por SIDA según regiones. Chile 2007-2011

\begin{tabular}{|c|c|c|c|c|c|c|c|c|c|c|}
\hline \multirow[t]{2}{*}{ Grupo edad } & \multicolumn{2}{|c|}{2007} & \multicolumn{2}{|c|}{2008} & \multicolumn{2}{|c|}{2009} & \multicolumn{2}{|c|}{2010} & \multicolumn{2}{|c|}{2011} \\
\hline & $\mathrm{N}^{\circ}$ & Tasa* & $\mathrm{N}^{\circ}$ & Tasa* & $\mathrm{N}^{\circ}$ & Tasa* & $\mathbf{N}^{\circ}$ & Tasa* & $\mathbf{N}^{\circ}$ & Tasa* \\
\hline Arica y Parinacota & 9 & 4,8 & 9 & 4,8 & 19 & 10,2 & 9 & 4,9 & 14 & 7,6 \\
\hline Tarapaca & 12 & 4,1 & 20 & 6,7 & 9 & 2,9 & 13 & 4,1 & 15 & 4,7 \\
\hline Antofagasta & 15 & 2,7 & 18 & 3,2 & 20 & 3,5 & 11 & 1,9 & 17 & 2,9 \\
\hline Atacama & 4 & 1,5 & 7 & 2,5 & 4 & 1,4 & 7 & 2,5 & 8 & 2,8 \\
\hline Coquimbo & 16 & 2,3 & 21 & 3,0 & 18 & 2,5 & 20 & 2,8 & 20 & 2,7 \\
\hline Valparaíso & 56 & 3,3 & 43 & 2,5 & 57 & 3,3 & 54 & 3,1 & 50 & 2,8 \\
\hline Metropolitana & 198 & 3,0 & 182 & 2,7 & 196 & 2,9 & 196 & 2,8 & 215 & 3,1 \\
\hline O’Higgins & 22 & 2,6 & 20 & 2,3 & 21 & 2,4 & 26 & 2,9 & 28 & 3,1 \\
\hline Maule & 17 & 1,7 & 17 & 1,7 & 29 & 2,9 & 22 & 2,2 & 29 & 2,9 \\
\hline Bío-Bío & 21 & 1,1 & 30 & 1,5 & 36 & 1,8 & 42 & 2,1 & 37 & 1,8 \\
\hline Araucanía & 8 & 0,8 & 6 & 0,6 & 6 & 0,6 & 10 & 1,0 & 11 & 1,1 \\
\hline Los Ríos & 2 & 0,5 & 3 & 0,8 & 5 & 1,3 & 2 & 0,5 & 3 & 0,8 \\
\hline Los Lagos & 18 & 2,2 & 14 & 1,7 & 13 & 1,6 & 19 & 2,3 & 20 & 2,4 \\
\hline Aisén & 0 & 0,0 & 1 & 1,0 & 1 & 1,0 & 2 & 1,9 & 2 & 1,9 \\
\hline Magallanes & 0 & 0,0 & 1 & 0,6 & 1 & 0,6 & 2 & 1,3 & 3 & 1,9 \\
\hline Total & 398 & 2,4 & 392 & 2,3 & 435 & 2,6 & 435 & 2,5 & 472 & 2,7 \\
\hline
\end{tabular}

Fuente:Base defunciones, DEIS, MINSAL.

*Tasa por cien mil habitantes. 


\section{Referencias bibliográficas}

1.- Programa Conjunto de las Naciones Unidas sobre el VIH/SIDA (ONUSIDA) Global report: UNAIDS report on the global AIDS epidemic 2013. Disponible en linea:http://www.unaids. org/en/media/unaids/contentassets/documents/ unaidspublication/2013/20101123 globalreport en.pdf.

2.- Conjunto de las Naciones Unidas sobre el VIH/SIDA (ONUSIDA), Informe de ONUSIDA para el Día Mundial del SIDA, 2011. Disponible en linea: http://www. unaids.org/en/media/unaids/contentassets/ documents/unaidspublication/2011/JC2216 WorldAIDSday_report_2011_es.pdf

3.- Organización Panamericana de la Salud (OPS), Fondo de Naciones Unidas para la Infancia (UNICEF), Programa Conjunto de las Naciones Unidas sobre el VIH/SIDA (ONUSIDA). Retos planteados por la epidemia del VIH en
América Latina y el Caribe 2009, Lima 2009. Disponible en linea: http://new.paho.org/hq/ index.php?option $=$ com_content $\&$ task $=$ view\&id $=2034$ \&Itemid $=1777$

4.- Comisión sobre Determinantes Sociales de la Salud. Lograr la equidad en salud: desde las causas iniciales a los resultados justos, declaración provisional [monografía en Internet]. Ginebra: Organización Mundial de la Salud; 2013. Disponible en línea: http://www. who.int/social_determinants/es/, (consultado el 16 de octubre de 2013).

5.- ONUSIDA. Estimaciones sobre VIH y el SIDA. Disponible en línea http://www.unaids. org/es/regionscountries/countries/chile/

6.- Ministerio de Salud. Decreto Supremo $N^{\circ} 158 / 2004$. Reglamento sobre notificación de Enfermedades transmisibles de declaración obligatoria. Santiago, Chile, mayo de 2005.

7.- Instituto de Salud Pública de Chile. Resultados confirmación de infección por VIH. Chile,
2009-2012. Boletín Vol. 3, N² 2, Enero de 2013 Disponible en línea: http://www.ispch.cl/sites/ default/files/Bolet\%C3\%ADn\%20VIH\%200802-2013_0.pdf

8.- Ministerio de Salud de Chile. Manual de procedimientos para la detección y diagnóstico de la infección por VIH 2010.

9.- Grupo SIDA Chile-Comisión Nacional del SIDA, Ministerio de Salud. Estudio de Cohorte de Personas que Viven con VIH en Tratamiento Antirretroviral, 2008.

10.- Séptima Encuesta Nacional de Juventud (INJUV). Publicado en Agosto de 2012 ISBN 978-956-7636-19-8. Disponible en línea: http://www.injuv.gob.cl/portal/wp-content/ files_mf/septimaencuestanacionaljuventud2.pdf, (consultada el 1 de octubre de 2013).

11.- Perfil consultante CRIPAC. Área de estudios, unidad de Epidemiología. Departamento de Salud pública. SEREMI de Salud Arica y Parinacota. 